\title{
RESEARCH
}

Open Access

\section{Chemokines modulate the tumour microenvironment in pituitary neuroendocrine tumours}

Pedro Marques', Sayka Barry ${ }^{1}$, Eivind Carlsen², David Collier ${ }^{1}$, Amy Ronaldson¹, Sherine Awad', Neil Dorward ${ }^{3}$, Joan Grieve ${ }^{3}$, Nigel Mendoza ${ }^{4}$, Samiul Muquit ${ }^{5}$, Ashley B. Grossman ${ }^{1}$, Frances Balkwill ${ }^{6}$ and Márta Korbonits ${ }^{1 *}$ (D)

\begin{abstract}
Non-tumoural cells within the tumour microenvironment (TME) influence tumour proliferation, invasiveness and angiogenesis. Little is known about TME in pituitary neuroendocrine tumours (PitNETs). We aimed to characterise the role of TME in the aggressive behaviour of PitNETs, focusing on immune cells and cytokines. The cytokine secretome of 16 clinically non-functioning PitNETs (NF-PitNETs) and 8 somatotropinomas was assessed in primary culture using an immunoassay panel with 42 cytokines. This was correlated with macrophage (CD68, HLA-DR, CD163), T-lymphocyte (CD8, CD4, FOXP3), B-lymphocyte (CD20), neutrophil (neutrophil elastase) and endothelial cells (CD31) content, compared to normal pituitaries (NPs, $n=5)$. In vitro tumour-macrophage interactions were assessed by conditioned medium (CM) of GH3 (pituitary tumour) and RAW264.7 (macrophage) cell lines on morphology, migration/invasion, epithelial-to-mesenchymal transition and cytokine secretion. IL-8, CCL2, CCL3, CCL4, CXCL10, CCL22 and CXCL1 are the main PitNET-derived cytokines. PitNETs with increased macrophage and neutrophil content had higher IL-8, CCL2, CCL3, CCL4 and CXCL1 levels. CD8+ T-lymphocytes were associated to higher CCL2, CCL4 and VEGF-A levels. PitNETs had more macrophages than NPs $(p<0.001)$, with a 3-fold increased CD163:HLA-DR macrophage ratio. PitNETs contained more CD4+ T-lymphocytes $(p=0.005)$, but fewer neutrophils $(p=0.047)$ with a 2 -fold decreased CD8:CD4 ratio. NF-PitNETs secreted more cytokines and had 9 times more neutrophils than somatotropinomas $(p=0.002)$. PitNETs with higher Ki-67 had more FOXP3+ T cells, as well as lower CD68:FOXP3, CD8:CD4 and CD8:FOXP3 ratios. PitNETs with "deleterious immune phenotype" (CD68 ${ }^{\text {hi }} C D 4^{\text {hi }} F O X P 3^{\text {hi }} C D 20^{\text {hi }}$ ) had a Ki-67 $\geq 3 \%$. CD163:HLA-DR macrophage ratio was positively correlated with microvessel density $(p=0.015)$ and area $(p<0.001)$. GH3 cell-CM increased macrophage chemotaxis, while macrophage-CM changed morphology, invasion, epithelial-to-mesenchymal transition and secreted cytokines of GH3 cells. PitNETs are characterised by increased CD163:HLA-DR macrophage and reduced CD8:CD4 and CD8: FOXP3 T cell ratios. PitNET-derived chemokines facilitate macrophage, neutrophil and $T$ cell recruitment into the tumours which can determine aggressive behaviour.
\end{abstract}

Keywords: Pituitary neuroendocrine tumour, Pituitary adenoma, Tumour microenvironment, Cytokine, Chemokine, Immune cell, Macrophages, Lymphocytes, Neutrophils, Epithelial-to-mesenchymal transition

\footnotetext{
* Correspondence: m.korbonits@qmul.ac.uk

${ }^{1}$ Centre for Endocrinology, William Harvey Research Institute, Barts and the London School of Medicine and Dentistry, Queen Mary University of London, London, UK

Full list of author information is available at the end of the article
}

(c) The Author(s). 2019 Open Access This article is distributed under the terms of the Creative Commons Attribution 4.0 International License (http://creativecommons.org/licenses/by/4.0/), which permits unrestricted use, distribution, and reproduction in any medium, provided you give appropriate credit to the original author(s) and the source, provide a link to the Creative Commons license, and indicate if changes were made. The Creative Commons Public Domain Dedication waiver (http://creativecommons.org/publicdomain/zero/1.0/) applies to the data made available in this article, unless otherwise stated. 


\section{Introduction}

Pituitary neuroendocrine tumours (PitNETs) can be associated with significant morbidity due to mass effects on surrounding tissues and/or excessive or low hormone secretion $[3,46]$. Twenty to $45 \%$ are invasive and may exhibit aggressive behaviour with cavernous sinus invasion and high Ki-67, and are often refractory to conventional treatment with poorer outcomes and higher recurrence rates $[15,18,53,82]$.

The tumour microenvironment (TME) consists of neoplastic, immune and stromal cells together with enzymes, growth factors and cytokines within the extracellular matrix $[5-7,11,24]$. Chemokines produced by the neoplastic cells contribute to trafficking and modulation of immune cells, angiogenesis and tumour invasion [5, 89]. Macrophages are a major component of the TME and are characterised by a spectrum of markers representing classically-activated macrophages (known as M1-like macrophages as one end of a spectrum) characterised by, among others, HLA-DR positivity [42, 44, 71], and alternatively-activated macrophages (representing another end, known as M2-like macrophages) characterised by, among others, CD163 positivity [27, 44, 81]. HLA-DR+ (M1-like) macrophages have an antitumoural effect $[27,60]$, whereas CD163+ (M2-like) macrophages are associated with tumour initiation, progression, invasion and angiogenesis [42, 44, 66, 73, 87]. Although the M1 and M2 macrophage nomenclature has been suggested to be replaced by more nuanced nomenclature [55], we use these forms when relating to previous literature $[42,44,66$, 73 , 87]. Tumour-infiltrating CD8+ T lymphocytes are usually beneficial to the host as they initiate cytotoxic cascades against tumour cells; CD4+ T helper 1 cells are associated with good outcomes, whereas CD4+ T helper 2 and FOXP3+ T regulatory cells are immunosuppressive [6, 9]; B lymphocytes are often associated with a good prognosis, but an immunosuppressive B cell population has also been described $[4,49,59,69]$. Neutrophils orchestrate responses against tumour cells, however, their role in tumour biology also includes detrimental effects [16, 61].

TME elements influence PitNET aggressiveness, rendering tumours larger $[37,91]$, more proliferative $[8,52]$ and invasive $[38,62,88,90]$. Studying the TME may provide novel insights into PitNET biology and may lead to development of novel therapies, such as the successful ipilimumab and nivolumab combined treatment in a patient with an ACTH-secreting pituitary carcinoma [35]. Previous studies have assessed CXCL12 [8, 19, 33, 48, $58,88,91]$, IL-8 [23, 76, 84] and immune cells [6, 37, 38, $52,85]$ in PitNETs. However, the crosstalk between the cytokine network and immune cells in determining the PitNET phenotype has not been previously comprehensively explored. In this study we aimed to characterise the cytokine network and the immune cell infiltrates within the TME of PitNETs.

\section{Materials and methods}

\section{Human PitNET samples}

Fresh human PitNET tissues from 24 patients (8 somatotropinomas and 16 clinically non-functioning PitNETs (NF-PitNETs), including 13 gonadotropinomas, 1 silent corticotropinoma and 2 null cell PitNETs) were obtained at the time of transsphenoidal surgery (Table 1), and a fragment was processed for primary culture. This study was approved by the local Ethics Committee (MREC No. 06/Q0104/133) and patients gave written informed consent. Normal pituitary (NP) autopsy samples collected 4$24 \mathrm{~h}$ post-mortem from subjects (age 18-81yr) with no known endocrine, immune or malignant disease $(n=5)$.

\section{Immunohistochemical analysis and evaluation}

Immunostains were performed on $4 \mu \mathrm{m}$ paraffinembedded tissue sections using Ventana Discovery DAB Map System (Ventana, Illkirch, France). Slides were deparaffinised and processed for antigen retrieval for 30 min with cell conditioning solution CC1 (Ventana), which is a Tris base buffer $(\mathrm{pH} \sim 9)$. After blocking with Blocker D solution (Ventana), slides were incubated with primary antibody for $60 \mathrm{~min}$ (Additional file 4: Table S1) and then with the universal secondary antibody (Ventana) for $20 \mathrm{~min}$. Slides were counterstained with haematoxylin. A negative control, where primary antibody was omitted, was included per experiment. Immunohistochemical studies assessed macrophages using CD68, CD163 and HLA-DR [42, 44, 71, 81], lymphocytes using CD8 for cytotoxic $\mathrm{T}$ cells, CD4 for $\mathrm{T}$ helper cells, FOXP3 for T regulatory cells and CD20 for B cells. Neutrophils were assessed with neutrophil elastase and endothelial cells with CD31 as well as by their location and morphology. Slides were scanned and analysed with Pannoramic Scanner and Viewer Software (3DHIS$\mathrm{TECH}$, Budapest, Hungary). Full stained slides were inspected at low magnification (5x and 10x magnification) in order to identify "hot spots" areas, i.e. areas with high abundance of immunopositive cells within the tumoural tissue in PitNET slides and within the normal pituitary tissue in NP slides. All selected areas were first verified on the respective haematoxylin and eosin slides, to ensure that cell counting was correctly performed in tumoural or normal pituitary tissue respectively. We excluded intra-vascular and non-adenomatous immunopositive cells. Immunopositive cells were counted in 5 different "hot spots" high power field (HPF) using the ImageJ software (National Institutes of Health, USA). Counterstained nuclei identifying tumour cells were also counted, and the data were expressed as percentage of immunopositive immune cells relatively to the total number of tumour cells per HPF. Vessels (stained for CD31) were manually counted in 3-5 different "hot spot" fields (20x magnification) allowing the estimation 
Table 1 Baseline clinicopathological features of the 24 patients with PitNETs

\begin{tabular}{|c|c|c|}
\hline & & $\begin{array}{l}\text { Total of PitNETs } \\
(n=24)\end{array}$ \\
\hline \multicolumn{3}{|l|}{ Gender $[n(\%)]$} \\
\hline \multicolumn{2}{|l|}{ Male } & $16(66.7 \%)$ \\
\hline \multicolumn{2}{|l|}{ Female } & $8(33.3 \%)$ \\
\hline \multicolumn{2}{|l|}{$\begin{array}{l}\text { Current age }(y r)[\text { mean } \pm \\
\text { standard deviation }(S D)]\end{array}$} & $51.9 \pm 15.1$ \\
\hline \multicolumn{2}{|l|}{$\begin{array}{l}\text { Age at diagnosis } \\
\text { (yr) [mean } \pm S D]\end{array}$} & $48.8 \pm 15.5$ \\
\hline \multicolumn{3}{|l|}{ Clinical diagnosis [n (\%)] } \\
\hline \multicolumn{2}{|l|}{ Acromegaly } & $8(33.3 \%)$ \\
\hline \multicolumn{2}{|l|}{ NF-PitNET } & $16(66.7 \%)$ \\
\hline \multicolumn{2}{|l|}{$\begin{array}{l}\text { Hyperprolactinaemia } \\
\text { at diagnosis [n (\%)] }\end{array}$} & $8(33.3 \%)$ \\
\hline \multicolumn{2}{|l|}{ Headache $[n(\%)]$} & $8(33.3 \%)$ \\
\hline \multicolumn{2}{|l|}{ Visual Impairment [n (\%)] } & $13(54.2 \%)$ \\
\hline \multicolumn{2}{|l|}{$\begin{array}{l}\text { Hypopituitarism at } \\
\text { diagnosis }[n(\%)]\end{array}$} & $11(45.8 \%)$ \\
\hline \multicolumn{2}{|l|}{ Macroadenoma [n (\%)] } & $24(100 \%)$ \\
\hline \multicolumn{2}{|l|}{$\begin{array}{l}\text { Suprasellar } \\
\text { extension [n (\%)] }\end{array}$} & $24(100 \%)$ \\
\hline \multicolumn{2}{|l|}{$\begin{array}{l}\text { Cavernous sinus } \\
\text { invasion }[n(\%)]\end{array}$} & $10(41.7 \%)$ \\
\hline \multicolumn{2}{|l|}{ Ki-67 $\geq 3 \%[n(\%)]$} & $5(20.8 \%)$ \\
\hline \multicolumn{2}{|l|}{$\begin{array}{l}\text { Mean number of } \\
\text { treatments [mean } \pm S D]\end{array}$} & $1.6 \pm 0.9$ \\
\hline \multicolumn{2}{|l|}{$\begin{array}{l}\text { Mean number of } \\
\text { surgeries [mean } \pm S D \text { ] }\end{array}$} & $1.2 \pm 0.5$ \\
\hline \multicolumn{2}{|l|}{ Reoperation [n (\%)] } & $5(20.8 \%)$ \\
\hline \multicolumn{2}{|l|}{$\begin{array}{l}\text { Hypopituitarism at } \\
\text { last follow-up [n (\%)] }\end{array}$} & $14(58.3 \%)$ \\
\hline \multicolumn{2}{|l|}{$\begin{array}{l}\text { Active disease at } \\
\text { last follow-up [n (\%)] }\end{array}$} & $4(16.7 \%)$ \\
\hline \multicolumn{2}{|l|}{$\begin{array}{l}\text { Follow-up duration } \\
\text { (yr) }[\text { mean } \pm S D]\end{array}$} & $2.5 \pm 9.1$ \\
\hline \multicolumn{3}{|c|}{$\begin{array}{l}\text { Pre-operative haematological } \\
\text { parameters [mean } \pm S D]\end{array}$} \\
\hline $\begin{array}{l}\text { Red cell count }\left(10^{12} \text { / }\right. \\
\text { L) }\end{array}$ & $\begin{array}{l}\text { [Normal range (NR): M 4.4-5.8 / F } \\
3.95-5.15 \text { ] }\end{array}$ & $4.58 \pm 0.46$ \\
\hline $\begin{array}{l}\text { Haemoglobin } \\
(\mathrm{g} / \mathrm{L})\end{array}$ & [NR: M 130-170 / F 115-155] & $132.46 \pm 12.47$ \\
\hline Haematocrit (\%) & [NR: M 37-50 / F 33-45] & $40.24 \pm 3.79$ \\
\hline $\begin{array}{l}\text { White cell count } \\
\left(10^{9} / L\right)\end{array}$ & [NR: $3.0-10.0]$ & $7.08 \pm 3.39$ \\
\hline $\begin{array}{l}\text { Neutrophil count } \\
\left(10^{\prime} / \mathrm{L}\right)\end{array}$ & {$[N R: 2.0-7.5]$} & $3.73 \pm 1.51$ \\
\hline $\begin{array}{l}\text { Lymphocyte count } \\
\left(10^{9} / \mathrm{L}\right)\end{array}$ & [NR: 1.2-3.65] & $2.71 \pm 2.25$ \\
\hline $\begin{array}{l}\text { Monocyte count } \\
\left(10^{9} / L\right)\end{array}$ & {$[N R: 0.2-1.0]$} & $0.44 \pm 0.13$ \\
\hline $\begin{array}{l}\text { Eosinophil count } \\
\left(10^{9} / \mathrm{L}\right)\end{array}$ & {$[N R: 0.0-0.4]$} & $0.17 \pm 0.11$ \\
\hline $\begin{array}{l}\text { Basophil count }\left(10^{9} /\right. \\
\text { L) }\end{array}$ & [NR: $0.0-0.1]$ & $0.03 \pm 0.02$ \\
\hline Platelet count $\left(10^{9} / \mathrm{L}\right)$ & [NR: 150-400] & $234.96 \pm 62.18$ \\
\hline
\end{tabular}

of microvessel density (number of vessels per HPF), and the vessels contour was manually traced using the ImageJ software to obtain an estimation of the total microvessel area $\left(\mu \mathrm{m}^{2}\right)$, as described previously [78].

\section{Pre-operative haematological data collection}

Blood samples from each patient were routinely taken within 7-10 days before the pituitary surgery as part of the pre-operative work-up protocol. All the serum full blood counts were performed in a certified National Health Service laboratory in a standardised manner on a Sysmax automated counter.

\section{RNA in situ hybridisation with RNAscope}

IL- 8 and CCL2 and chemokine receptors CXCR2 and CCR5 were detected using the RNAscope 2.5 HD Duplex Chromogenic Assay (Advanced Cell Diagnostics, ACD, USA), according to the manufacturer's protocols. Briefly, $4 \mu \mathrm{m}$ paraffin-embedded PitNET tissue sections were baked at $60{ }^{\circ} \mathrm{C}$ for $90 \mathrm{~min}$, deparaffinised, and then boiled with pre-treatment retrieval reagent for $15 \mathrm{~min}$. Protease digestion was performed at $40{ }^{\circ} \mathrm{C}$ for $30 \mathrm{~min}$, followed by hybridisation for $2 \mathrm{~h}$ at $40{ }^{\circ} \mathrm{C}$ with Probe mix according to 1:50 ratio of $\mathrm{C} 2$ to $\mathrm{C} 1$ probes: mix IL-8 (ACD, cat. no. 310381-C2) and CXCR2 (ACD, cat. no. 468411), and mix CCR5 (ACD, cat. no. 601501-C2) and CCL2 (ACD, cat. no. 423811). Hybridisation signals were amplified and visualised with RNAscope 2.5 HD Duplex Chromogenic Assay reagents. Cell nuclei were counterstained with haematoxylin, and slides were mounted with VectaMount mounting medium (Vector Laboratories, cat. no. H-5000). Probe-DapB (ACD) was used as negative control. Slides were scanned and analysed with Pannoramic Scanner and Viewer Software (3DHISTECH, Budapest, Hungary).

\section{Primary culture}

Fresh PitNET tissue was collected in high glucose Dulbecco's Modified Eagle's Medium (DMEM, Sigma, Gillingham, UK, cat. no. D6429) supplemented with 10\% heat-inactivated foetal bovine serum (FBS, Gibco, Loughborough, UK, cat. no. 16000044) and 0.5\% gentamicin (Sigma, cat. no. G1397). Tissue was washed with magnesium and calcium-free Phosphate Buffered Saline (PBS) (Sigma, cat. no. D8537), cut into small pieces and incubated for $45 \mathrm{~min}$ at $37^{\circ} \mathrm{C}$ in 10 times diluted Trypsin-EDTA $0.05 \%$ (1X) Phenol Red (Gibco, cat. no. 25300054) with frequent pipetting allowing effective cell dispersion. Trypsin digestion was stopped by adding complete medium, cells were transferred to a tube and allowed to stand for $10 \mathrm{~min}$ for sedimentation of undigested debris. Supernatants containing tumour cells were transferred to a separate tube, centrifuged at $800 \mathrm{~g}$ for $5 \mathrm{~min}$, and gently re-suspended in $1 \mathrm{~mL}$ complete 
medium. Viable cells were assessed with Tryptan Blue Solution (Sigma, cat. no. T8154) and $2 \times 10^{6}$ cells were seeded in complete medium in a well coated with PolyL-lysine (Sigma, cat. no. P4707) from a 6-well plate when viability was $>90 \%$. Cells were incubated overnight at $5 \% \mathrm{CO}_{2}$ at $37^{\circ} \mathrm{C}$. The next day plates were examined under the microscope, complete medium was aspirated, cells were carefully washed 3 times with PBS, and then $1 \mathrm{~mL}$ serum-free medium was added. After incubation for $24 \mathrm{~h}$, supernatants were collected to clean tubes and placed immediately on ice to avoid cytokine degradation. Tubes were centrifuged at $10,000 \mathrm{rpm}$ for $10 \mathrm{~min}$ at $4{ }^{\circ} \mathrm{C}$ to remove debris, and supernatants were collected and stored in $-80{ }^{\circ} \mathrm{C}$ for $3-6$ months until being assayed in duplicate with the human Millipore MILLIPLEX cytokine 42-plex array.

\section{Cell culture}

Rat pituitary somatomammotroph GH3 cell line, obtained from European Collection of Authenticated Cell Cultures, and the murine RAW 264.7 macrophages (kind gift from Dr. Giulia Marelli, Barts Cancer Institute) were incubated at $5 \% \mathrm{CO}_{2}$ at $37^{\circ} \mathrm{C}$ and cultured in high glucose DMEM supplemented with 10\% FBS and 0.5\% gentamycin. Once cells were $70-90 \%$ confluent, they were passaged after washes with magnesium- and calcium-free PBS, and mobilisation with Trypsin-EDTA $0.05 \%$ (1X) Phenol-Red for GH3 cells or with Accutase ${ }^{\circ}$ solution (Sigma, cat. no. A6964) for RAW 264.7 macrophages. Once cells were detached (confirmed by light microscopy), cell suspension was put into new flasks or spun ( $3 \mathrm{~min}, 1200 \mathrm{~g}$ ) and re-suspended in medium to be further used in in vitro experiments.

$\mathrm{GH} 3$ cell-conditioned medium $(\mathrm{CM})$ was generated by seeding $5 \times 10^{6} \mathrm{GH} 3$ cells in T75 culture flasks for $72 \mathrm{~h}$ in $10 \mathrm{~mL}$ complete medium. Macrophage-CM was generated from $5 \times 10^{6}$ RAW 264.7 macrophages in T75 culture flasks for $24 \mathrm{~h}$ in $10 \mathrm{~mL}$ complete medium (-PMA_Raw.CM) or stimulated with $5 \mathrm{nM}$ of Phorbol 12-Myristate 13-Acetate (PMA) (Sigma, cat. no. P8139) in $10 \mathrm{~mL}$ complete medium (+PMA_Raw.CM).

Cell culture supernatants for cytokine array were generated by seeding $5 \times 10^{5}$ GH3 cells in 12-well culture plates for $24 \mathrm{~h}$ in serum-free medium conditions at baseline and after treatment with RAW 264.7 macrophageCM. Supernatants were carefully transferred to clean tubes, centrifuged at $10,000 \mathrm{rpm}$ for $10 \mathrm{~min}$ in $4{ }^{\circ} \mathrm{C}$ to remove debris, and then supernatants were collected and stored in $-80^{\circ} \mathrm{C}$ for $3-6$ months until being assayed.

\section{Human and rat Millipore MILLIPLEX cytokine arrays}

Cytokine arrays on human PitNET-derived supernatants were performed by Eve Technologies (Calgary, Alberta, Canada), according to their protocol by using Bio-Plex ${ }^{\text {Tx }}$
200 system (Bio-Rad Laboratories, Inc., Hercules, CA, USA), and human cytokine/chemokine array with IL-18 (HD42) kit (Millipore, St. Charles, USA). This array measured 42 different cytokines, chemokines and growth factors in the same sample: G-CSF, GM-CSF, IFN $\alpha 2$, IFN $\gamma$, IL-1 $\alpha$, IL-1 $\beta$, IL-1ra, IL-2, IL-3, IL-4, IL-5, IL-6, IL-7, IL-8, IL-9, IL-10, IL-12(p40), IL-12(p70), IL-13, IL15, IL-17A, IL-18, CXCL1, CXCL10, CCL2, CCL3, CCL4, CCL5, CCL7, CCL11, CCL22, CX3CL1, SCD40L, Flt-3 L, PDGF-AA, PDGF-BB, TGF- $\alpha$, TNF- $\alpha$, TNF- $\beta$, VEGF-A, EGF and FGF-2.

Millipore MILLIPLEX arrays on supernatants from rat GH3 cells were also performed by Eve Technologies, using a different species-specific kit array: rat cytokine/chemokine array 27-plex (RD27) (Millipore) able to measure 27 different cytokines, chemokines and growth factors in the same sample: G-CSF, GM-CSF, IFN $\gamma$, IL- $1 \alpha$, IL-1 $\beta$, IL-2, IL-4, IL-5, IL-6, IL-10, IL-12(p70), IL-13, IL-17A, IL-18, CXCL1, CXCL2, CXCL10, CCL2, CCL3, CCL5, CCL11, CX3CL1, TNF- $\alpha$, VEGF, EGF, Leptin and LIX.

\section{Invasion, migration and morphology studies}

Invasion assays were carried out using the BioCoat Matrigel Invasion Chambers with $8 \mu \mathrm{m}$ pores (24-well insert; BD Biosciences, CA, USA, cat. no. 354480). Invasion chambers were hydrated for $2 \mathrm{~h}$ with $500 \mu \mathrm{l}$ of serum-free medium at $37^{\circ} \mathrm{C}$. After Matrigel rehydration, $750 \mu \mathrm{l}$ of macrophage-CM or complete medium was added to the lower chamber as chemoattractant and $2.5 \times 10^{4} \mathrm{GH} 3$ cells in $500 \mu \mathrm{l}$ serum-free medium were added to the upper chamber and incubated at $37^{\circ} \mathrm{C}$. After $72 \mathrm{~h}$, invading cells through Matrigel were fixed in $100 \%$ methanol and stained with $2 \%$ Giemsa blue (Sigma-Aldrich, MO, USA, cat. no. G5637-5G). Total number of invading cells per chamber were counted, and normalised to invading cells towards complete medium. Macrophage chemotaxis were evaluated by Transwell BioCoat Migration insert plates with $8 \mu \mathrm{m}$ pores (24-well insert; Corning Fisher Scientific, USA, cat. no. 354578) following a similar protocol as described for invasion assay. Migration and invasion studies were run in duplicates and were repeated at least 3 times. Morphological changes were assessed, as previously described [10], by measuring 6 different shape parameters using Image): area (area of selection in calibrated square units, $\left.\mu \mathrm{m}^{2}\right)$; perimeter $(\mu \mathrm{m})$; Feret's diameter (longest distance between any 2 points along selection boundary); roundness (representing shape, $4 \times$ [Area] $/ \pi \times$ [Major axis $]^{2}$, with value of 1 for a circle and 0 for very elongated shapes); circularity (representing perimeter smoothness, $4 \pi \times[\text { Area] [Perimeter }]^{2}$, with value of 1 indicating a perfect circle and value close to 0 indicating elongated shape) and solidity (value of 1 indicating more stiffness and less deformable cells). Per treatment 
condition, 5 images at 40x were taken and 15 cells were measured per image, thus 75 cells were analysed per experiment (minimum of 3 experiments were done).

\section{Immunocytochemistry}

GH3 cells $\left(5 \times 10^{4}\right)$ were plated on $15 \mathrm{~mm}$ coverslips placed in 12-well plates. After overnight attachment, GH3 cells were treated with -PMA_Raw.CM, +PMA_Raw.CM or complete medium for $24 \mathrm{~h}$. Cells were fixed in $4 \%$ paraformaldehyde for $15 \mathrm{~min}$ at room temperature, following washes with PBS cells were permeabilised with $0.1 \%$ Triton X-100 in PBS for 5 min at $4{ }^{\circ} \mathrm{C}$. Cells were blocked in $1 \%$ bovine serum albumin for $30 \mathrm{~min}$ at room temperature, and then incubated with primary antibodies (listed in the Additional file 4: Table S1) followed by a 30 min incubation with secondary conjugated antibodies (Alexa Fluor 568-conjugated goat anti-mouse IgG, Alexa Fluor 488-conjugated donkey anti-mouse IgG and Alexa Fluor 488-conjugated donkey anti-rabbit IgG; 1:1000; Molecular Probes, Invitrogen). Coverslips with stained cells were mounted with Fluoroshield with DAPI mounting medium (Sigma, cat. no. F6057). Stained slides were visualised on confocal microscope LSM 880 Zeiss and images taken at 63x magnification. E-cadherin and ZEB1 fluorescent intensities were quantified using the software Carl Zeiss Zen Blue Edition v2.3.

\section{Real-time quantitative polymerase chain reaction (RT- qPCR)}

RNA from GH3 cells and RAW 264.7 macrophages was extracted using Qiagen's RNeasy micro kit (cat. no. 74004) according to manufacturer's protocol. RNA samples were assessed by NanoDrop ND-1000 spectrophotometer (NanoDrop Technologies, Rockland, DE, USA). Complementary DNA was synthesised from $1 \mu \mathrm{g}$ of RNA using High-Capacity cDNA Reverse Transcription Kit (Thermofisher Scientific, cat. no. 4374966) following the manufacturer's protocol. RT-qPCR reactions were prepared using Brilliant III Ultra-Fast SYBR Green QPCR Master Mix (Agilent Technologies, Palo Alto, CA, USA, cat. no. 600882) and run with Thermal Cycler with MxPro software (Agilent) using a 2-step programme: pre-incubation $3 \mathrm{~min}$ at $95^{\circ} \mathrm{C}$, then 40 cycles of 20 s at $95^{\circ} \mathrm{C}$ and $20 \mathrm{~s}$ at $60^{\circ} \mathrm{C}$. Cycle threshold (CT) values were analysed with $\Delta \Delta C T$ quantification method. Target gene expression was normalised to GAPDH expression used as internal control. Primers sequence (Sigma-Aldrich) were as follows: CCR5 forward 5'-GTATGTCAGCACCCTGCCAA-3', reverse 5'-GAGCAGGAAGAGCAGGTCAG-3'; CX3CR1 forward 5'-CCATCTGCTCAGGACCTCAC-3', reverse 5'-CACCAGACCGAACGTGAAGA-3'; MMP9 forward 5'-CTTGAAGTCTCAGAAGGTGGATC-3', reverse 5'CGCCAGAAGTATTTGTCATGG-3'.
Affymetrix microarray analysis and xCell deconvolution Total RNA from a different set of 7 human sporadic PitNET samples (3 somatotropinomas and 4 NF-PitNETs) and 5 NPs was isolated using the Qiagen's RNeasy micro kit and target labelling and hybridisation were performed using Affymetrix GeneChip 3' IVT Express Kit (Affymetrix, Santa Clara, CA, USA) according to manufacturer's instructions (samples described in detail in [10]). Microarray data have been deposited with the National Center for Biotechnology Information Gene Expression Omnibus (www.ncbi.nlm.nih. gov/geo, accession number GSE63357). For deconvolution, we used the gene-signature webtool method $x$ Cell $[2,56]$, which inferred different immune and stromal cells from microarray expression data giving a score per cell type. This tool uses the M1 and M2 macrophage nomenclature.

\section{Statistical analysis}

Statistical analyses were carried out using the SPSS statistical software v20 (IBM, USA) and GraphPad v6 (Prism, USA). Mann Whitney U test, one-way or twoway ANOVA tests with post-hoc comparison tests were applied as appropriate. Correlations between continuous variables were determined by Pearson correlation coefficient $r$. $p$ values $<0.05$ were considered significant.

\section{Results}

Pituitary tumour cells release chemokines, with NFPitNETs secreting higher amounts than somatotropinomas

In order to identify the most relevant cytokines derived from human PitNETs, we established primary cultures from 24 PitNETs. All tumours were larger than $1 \mathrm{~cm}$ in diameter, 10 had cavernous sinus invasion and 5 had Ki$67 \geq 3 \%$ (Table 1). We assessed 42 different cytokines in fresh tumour culture supernatants (Additional file 5: Table S2). The cytokine array identified IL-8, CCL2, CCL3, CCL4, CXCL10, CCL22, CXCL1 and CX3CL1 as the main PitNET-derived cytokines (Table 2), all chemokines specialised in immune cell recruitment [5]. Ninety percent of PitNETs secreted IL-8, CCL2 and CCL3, while CXCL1 was secreted by $50 \%$ of the tumours (Table 2). RNAscope data showed that CCL2 and IL-8 are mainly synthesised by pituitary tumour cells, while these have low expression of chemokine receptors; chemokine receptors were, in turn, strongly expressed in scattered perivascular cells, morphologically distinct from tumour cells, likely corresponding to immune cells (Fig. 1a).

NF-PitNETs secreted higher amounts of cytokines/chemokines than somatotropinomas, especially CCL2 (16x more), IL-8 (25x more) and CCL4 (27x more), except for FGF-2 which was found in higher concentrations in somatotropinoma supernatants (Fig. 1b). NF-PitNETs were more often secreting IL-8, CCL2, CCL4, IL-6 and PDGF-AA than somatotropinomas (Fig. 1c). Secretome differences between 
Table 2 Top 12 highly secreted cytokines/chemokines/growth factors in the human PitNETs-derived cell culture supernatants ( $n=$

\begin{tabular}{llll} 
24) & & & \\
Cytokine/ Chemokine/ & $\begin{array}{l}\text { Mean concentration } \\
(\mathrm{pg} / \mathrm{mL}) \pm \text { SEM }\end{array}$ & $\begin{array}{l}\text { Serum-free } \\
\text { medium }(\mathrm{pg} / \mathrm{mL})\end{array}$ & $\begin{array}{l}\mathrm{n}(\%) \text { of PitNETs with } \\
\text { detectable cytokine }\end{array}$ \\
\hline IL-8 & $854.18 \pm 445.79$ & 7.06 & $22(91.7 \%)$ \\
CCL2 & $578.03 \pm 222.66$ & 4.00 & $21(87.5 \%)$ \\
CCL3 & $150.55 \pm 88.22$ & 0 & $22(91.7 \%)$ \\
CCL4 & $94.25 \pm 47.20$ & 3.09 & $18(75.0 \%)$ \\
CXCL10 & $76.67 \pm 47.58$ & 0 & $14(58.3 \%)$ \\
CCL22 & $67.25 \pm 16.74$ & 20.78 & $15(62.5 \%)$ \\
CXCL1 & $60.30 \pm 26.14$ & 20.78 & $12(50.0 \%)$ \\
CX3CL1 & $35.14 \pm 17.12$ & 6.73 & $19(79.2 \%)$ \\
FGF-2 & $26.65 \pm 4.11$ & 0 & $19(79.2 \%)$ \\
IL-6 & $24.90 \pm 19.27$ & 0 & $12(50.0 \%)$ \\
PDGF-AA & $22.36 \pm 6.78$ & 0.12 & $20(83.3 \%)$ \\
VEGF-A & $15.85 \pm 4.06$ & 0 & $18(75.0 \%)$
\end{tabular}

PitNETs-derived supernatants collected at $24 \mathrm{~h}$ on serum-free medium conditions and cytokine secretome determined with the human Millipore MILLIPLEX cytokine 42-plex array. Data are shown as mean concentration $(\mathrm{pg} / \mathrm{mL}) \pm$ standard error of the mean (SEM). Right column shows the number and percentage of PitNETs with detectable cytokine levels, i.e. cytokine concentration above the lowest standard curve point and serum-free medium quantification

NF-PitNETs and somatotropinomas were not explained by pre-operative somatostatin analogue treatment, as there were no secretome differences between pre-treated and non-pre-treated somatotropinomas (Additional file 1: Figure S1a). There were also no secretome differences between sparsely and densely granulated somatotropinomas (Additional file 1: Figure S1b). The PitNET-derived cytokine secretome was not associated per se with cavernous sinus invasion, elevated $\mathrm{Ki}-67$ or presence of hypopituitarism at diagnosis (data not shown).

\section{Immune infiltrates differ between PitNETs and NPs}

PitNETs contained more CD68+ macrophages $(4.6 \pm 0.4$ vs $1.2 \pm 0.2 \%, p<0.001)$ and CD $4+\mathrm{T}$ cells $(1.0 \pm 0.1$ vs $0.6 \pm 0.1 \%, p=0.005)$, but fewer neutrophils $(0.7 \pm 0.2$ vs $1.4 \pm 0.1 \%, p=0.047)$ and a trend for fewer CD8+ T cells $(1.8 \pm 0.2$ vs $2.6 \pm 0.3 \%, p=0.077)$, with a significant 2 fold decrease in the CD8:CD4 cell ratio compared to NPs (Fig. 2). There were no significant differences in $B$ and FOXP3+ T cells content (Fig. 2).

Macrophages are the most abundant immune cell type in PitNETs, while other immune cells are present in lower amounts (Fig. 2). Macrophages in PitNETs are predominantly CD163+, while HLA-DR+ macrophages predominate in NPs, resulting in a 3-fold increase in the CD163:HLADR macrophage ratio in PitNETs (Fig. 3a). These immunohistochemical findings were confirmed on a different set of samples [10] using gene expression analysis with xCell, with PitNETs having a higher score than NPs for macrophages $(0.090 \pm 0.016$ vs $0.031 \pm 0.013 ; p=0.025)$ and CD163+ macrophages $(0.042 \pm 0.007 \mathrm{vs} 0 ; p=0.001)$ (Additional file 2: Figure S2). The CD163+ macrophage phenotype in PitNETs may be due, at least in part, to higher concentrations of PitNET-derived M2-polarising cytokines, as IL-4 levels were almost $5 \mathrm{x}$ higher than interferon- $\gamma$ (M1-polarising cytokine) (Fig. 3b).

We observed significant correlations between infiltrating immune cell populations in PitNETs, namely between CD8+ and CD4+ $\mathrm{T}$ cells $(r=0.534 ; p=0.007)$, CD8+ and FOXP3+ T cells $(r=0.504 ; p=0.012), \mathrm{CD} 4+$ $\mathrm{T}$ cells and neutrophils $(r=0.490 ; p=0.05)$.

NF-PitNETs had more neutrophils than somatotropinomas $(0.9 \pm 0.1$ vs $0.1 \pm 0.1 \%, p=0.002)$, but there were no differences regarding other immune cells, neither CD163: HLA-DR, CD8:CD4 or CD8:FOXP3 cell ratios (Additional file 6: Table S3). There were no significant differences in infiltrating immune cells among the different NF-PitNET types (Additional file 6: Table S3) or between sparsely and densely granulated somatotropinomas (data not shown).

\section{Tumour cell-derived cytokines attract immune cells into the TME}

PitNETs with higher macrophage content were associated to higher levels of IL-8 $(p=0.023)$, CCL2 $(p=$ $0.216)$, CCL3 $(p=0.065)$, CCL4 $(p=0.036)$ and CXCL1 $(p=0.024)$ (Fig. 4a), chemokines known to promote macrophage chemotaxis $[1,5,41,43]$. We observed higher CCL2 $(\mathrm{p}=0.036)$, CCL4 $(p=0.086)$, CXCL10 $(p=0.134)$ and VEGF-A $(p=0.025)$ levels in the supernatants from PitNETs with higher CD8 $+\mathrm{T}$ cell contents (Fig. 4b). PitNETs with more neutrophils released higher levels of CCL2 $(p=0.033)$ and CCL4 $(p=0.044)$, cytokines known to attract neutrophils $[16,63,92]$, and there was a noteworthy trend to release higher levels of chemokines involved in neutrophil chemotaxis (Fig. 4c), 

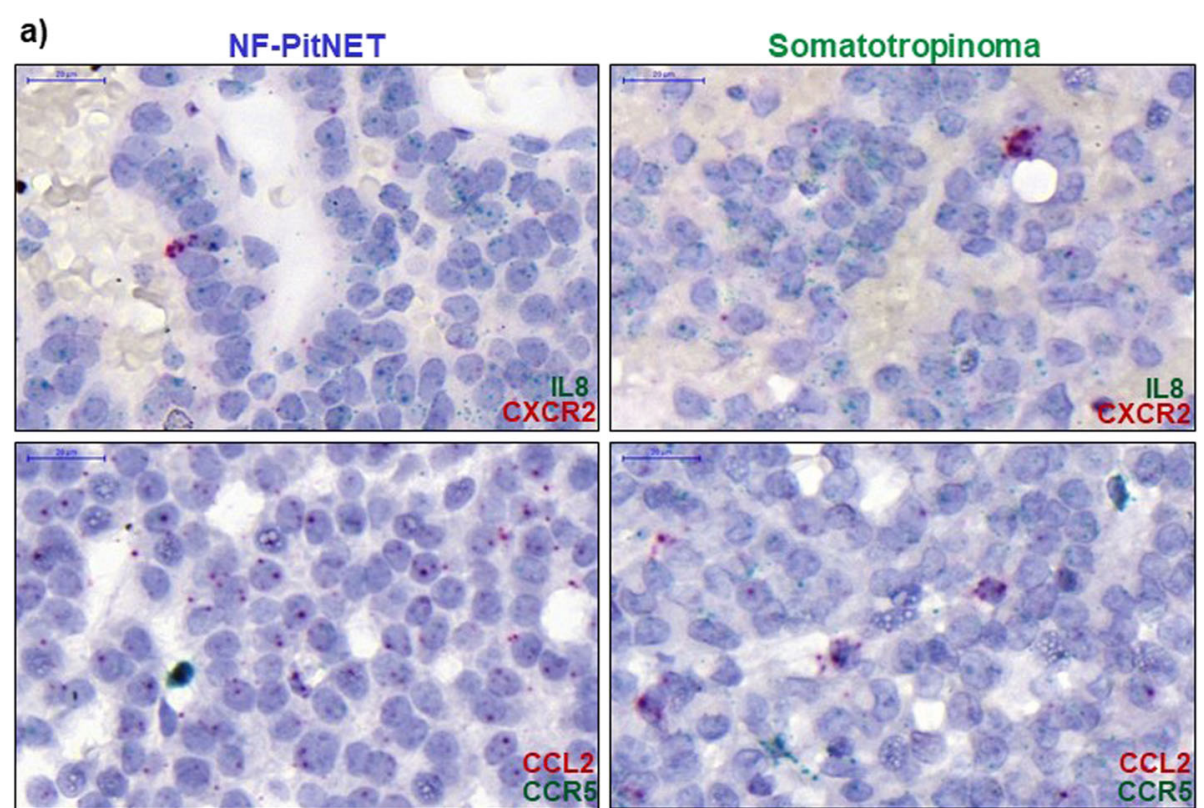

\section{(1)}
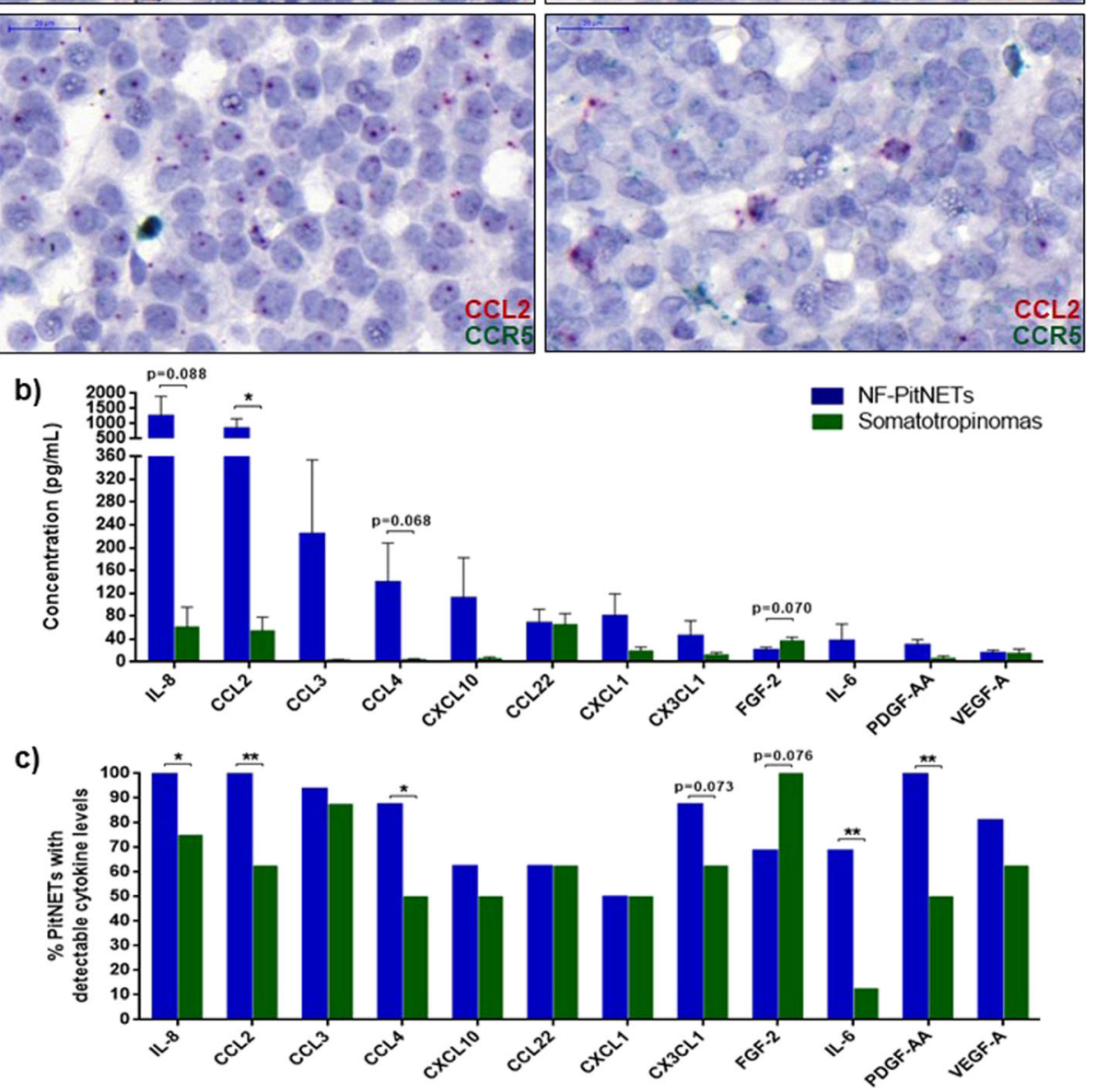

Fig. 1 a RNAscope staining of IL8 (green)-CXCR2 (red) and CCL2 (red)-CCR5 (green) mRNA in a NF-PitNET and a somatotropinoma. CCL2 and IL-8 are mainly expressed in pituitary tumour cells, while the chemokine receptors are strongly expressed in scattered perivascular cells (morphologically distinct from tumour cells), likely corresponding to immune cells. Scale bar $20 \mu \mathrm{m}$. $\mathbf{b}$ Cytokine secretome from NF-PitNETs $(n=$ 16) and somatotropinomas $(n=8)$. Data are shown for the top 12 secreted proteins as mean \pm standard error of the mean. ${ }^{*},<0.05$ (Mann Whitney $\mathrm{U}$ test). c Percentage of NF-PitNETs $(n=16)$ and somatotropinomas $(n=8)$ with detectable cytokine levels, i.e. concentration above the lowest standard curve and serum-free medium quantification. Data are shown as percentage and for the top 12 secreted proteins as identified by the Millipore MILLIPLEX assay in primary culture supernatants. ${ }^{*},<0.05,{ }^{* *},<0.01$ (Chi-squared test)

namely IL-8 $(p=0.073)$, CXCL1 $(p=0.097)$ and CXCL10 $(p=0.098)$. There were no significant associations between PitNET-derived cytokine secretome and infiltrating CD4+, FOXP3+ and B cells (data not shown).

PitNET-infiltrating immune cells did not correlate with circulating immune cell types, suggesting that immune infiltrates are subject to differential recruitment into the PitNET rather than altered bone marrow production (Additional file 3: Figure S3).

\section{Immune cells in the TME of PitNETs may determine} tumour proliferation and angiogenesis

PitNETs with higher proliferative index (Ki-67 $\geq 3 \%$ ) had lower CD8:CD4 ratio, as well as lower CD8:FOXP3 and 

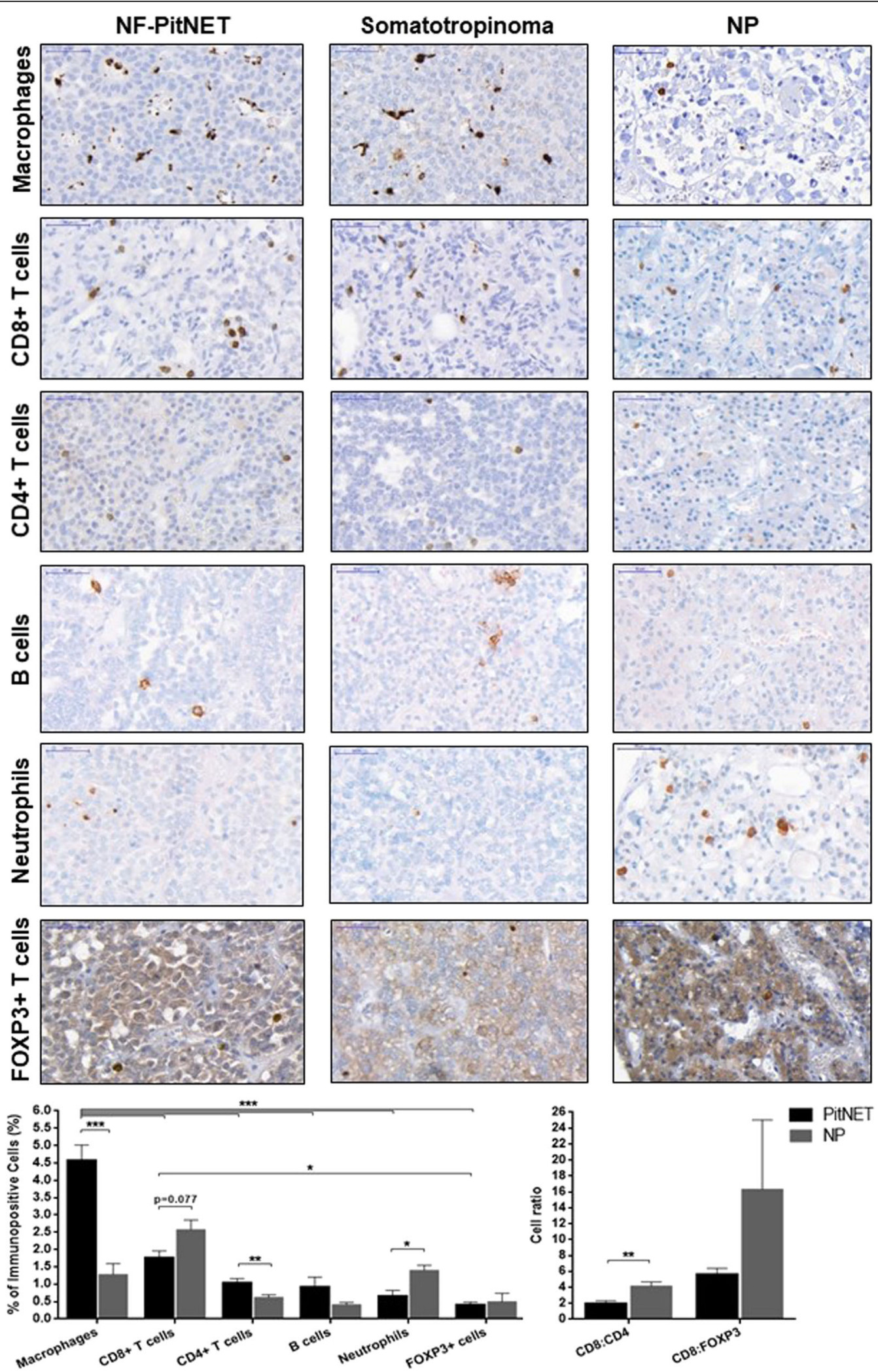

Fig. 2 (See legend on next page.) 
(See figure on previous page.)

Fig. 2 Immunohistochemical analysis of immune cells in PitNETs and normal pituitary (NP). Immune cells analysed: macrophages (CD68+), cytotoxic T lymphocytes (CD8+), T helper lymphocytes (CD4+), T regulatory cells (FOXP3+), B cells (CD20+) and neutrophils (neutrophil elastase+). Data are shown as mean \pm standard error of the mean for percentage of immune cells compared to the total number of tumour cells, and for CD8:CD4 or CD8:FOXP3 cell ratios. Representative images are shown for NF-PitNET, somatotropinoma and NP. Scale bar $50 \mu m$. PitNETs, $n=24 ;$ NPs, $n=5 .{ }^{*},<0.05,{ }^{* *},<0.01,{ }^{* * *},<0.001$ (two-way ANOVA with Bonferroni multiple comparison test for immunopositive cell comparative analysis; Mann Whitney $U$ test for cell ratio comparative analysis)

CD68:FOXP3 ratios as a result of increased infiltration of FOXP3+ T cells $(0.7 \pm 0.2$ vs $0.3 \pm 0.6 \% ; p=0.013)$ (Fig. $5 a-$ b). All PitNETs with "deleterious immune infiltrate phenotype", i.e. higher content of macrophages, $\mathrm{T}$ helper lymphocytes, FOXP3+ $\mathrm{T}$ regulatory cells and $\mathrm{B}$ cells $\left(\mathrm{CD} 68^{\text {hi }} \mathrm{CD} 4^{\text {hi }} \mathrm{FOXP} 3{ }^{\text {hi }} \mathrm{CD} 20^{\mathrm{hi}}\right.$ ) had a Ki-67 $\geq 3 \%$ (Fig. $5 \mathrm{c}$ ). There were no differences between PitNETs with or without cavernous sinus invasion regarding immune cell content or cell ratios (data not shown). The CD163:HLADR macrophage ratio was positively correlated with microvessel density $(p=0.015)$ and area $(p<0.001)$ (Fig. 6).

GH3 cell-derived factors increase macrophage chemotaxis and alter their morphology

To study the interactions between pituitary tumour cells (GH3 mammosomatotroph tumour cell line)
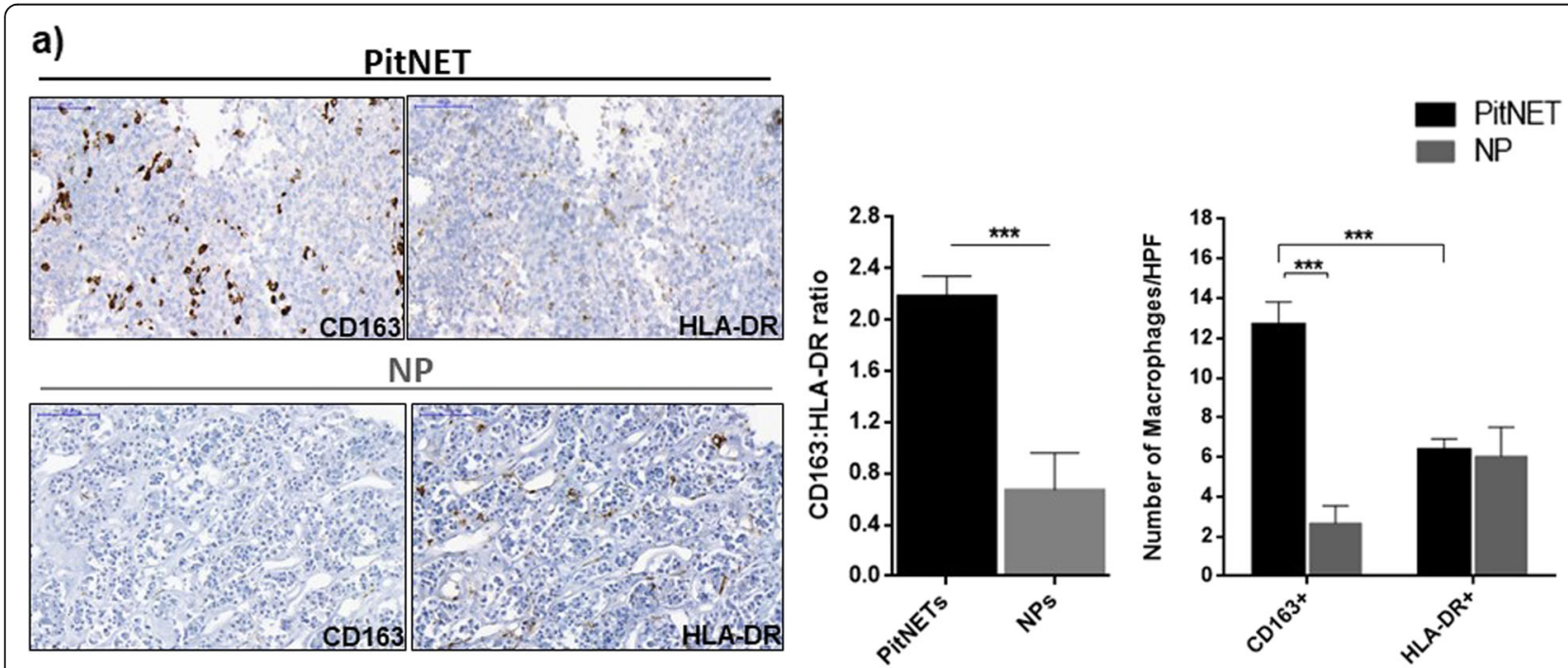

b)

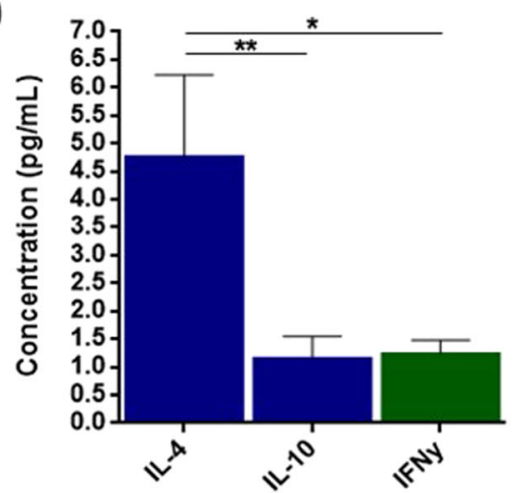

Fig. 3 a Immunohistochemical analysis of CD163+ and HLA-DR+ macrophages in PitNETs and normal pituitary (NP). Data are shown as mean \pm standard error of the mean (SEM) for CD163:HLA-DR ratio and for the number of CD163-positive and HLA-DR-positive cells per high power field (HPF). Representative images are shown for a PitNET and NP. Scale bar $50 \mu \mathrm{m}$. PitNETs, $n=24 ; \mathrm{NP}, n=5$. ***, $<0.001$ (Mann Whitney U test). b Macrophage-polarising cytokines in PitNET culture supernatants. Supernatants were collected at $24 \mathrm{~h}$ in serum-free medium conditions and cytokine secretome determined with the human Millipore MILLIPLEX cytokine 42-plex array. Results are shown as mean \pm SEM for IL-4 and IL-10 (M2-polarising cytokines, blue bars) and IFNy (M1-polarising cytokine, green bar). ${ }^{*},<0.05,{ }^{* *},<0.01$ (one-way ANOVA with Bonferroni multiple comparison test) 
a) Secretome from PitNETs with lower $(<6 \%)$ vs higher $(\geq 6 \%)$ macrophages content

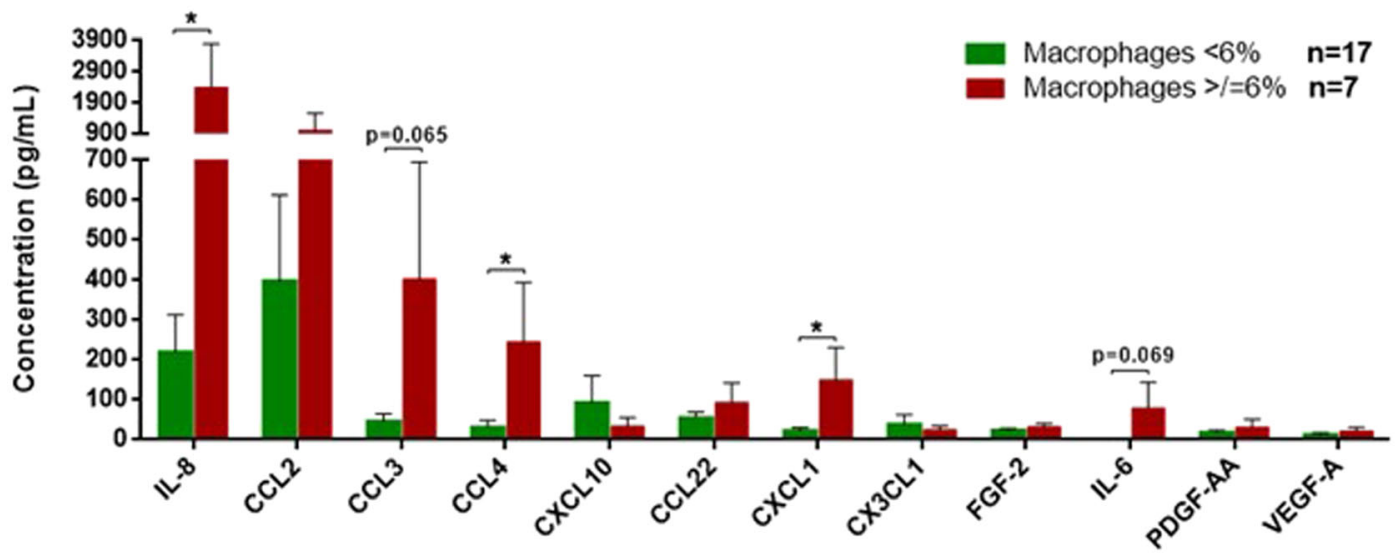

b) Secretome from PitNETs with lower $(<1 \%)$ vs higher $(\geq 1 \%)$ CD $8+$ T cells content

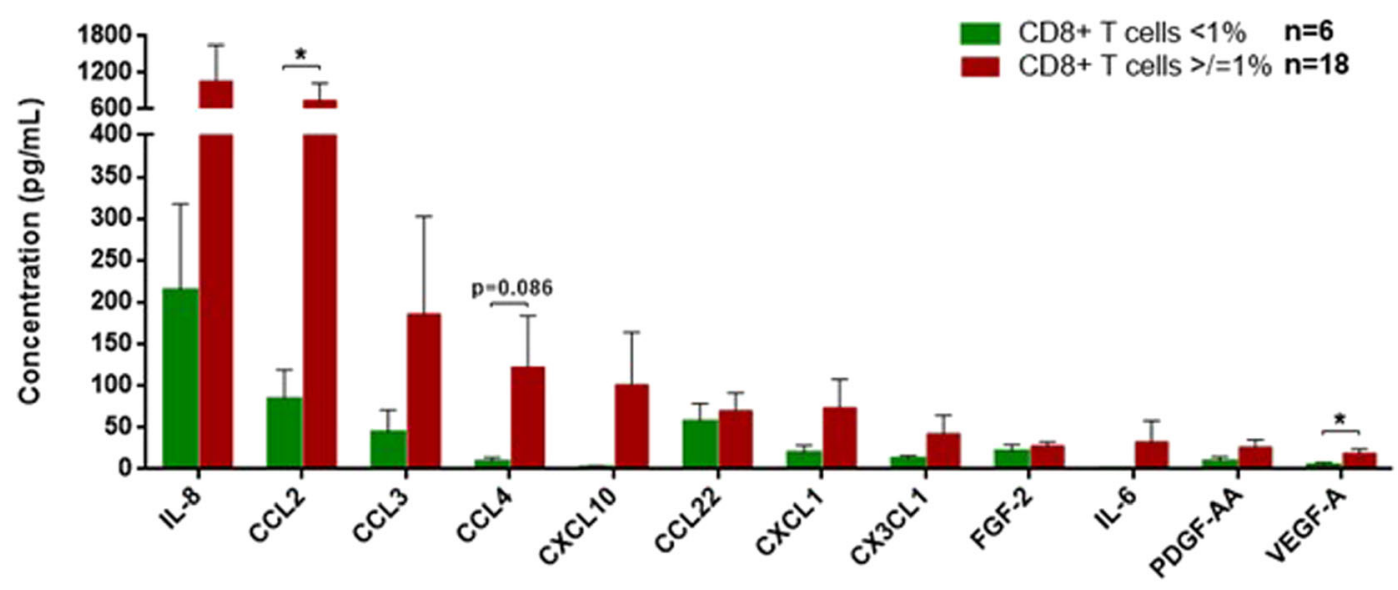

C) Secretome from PitNETs with lower $(<0.5 \%)$ vs higher $(\geq 0.5 \%)$ neutrophils content

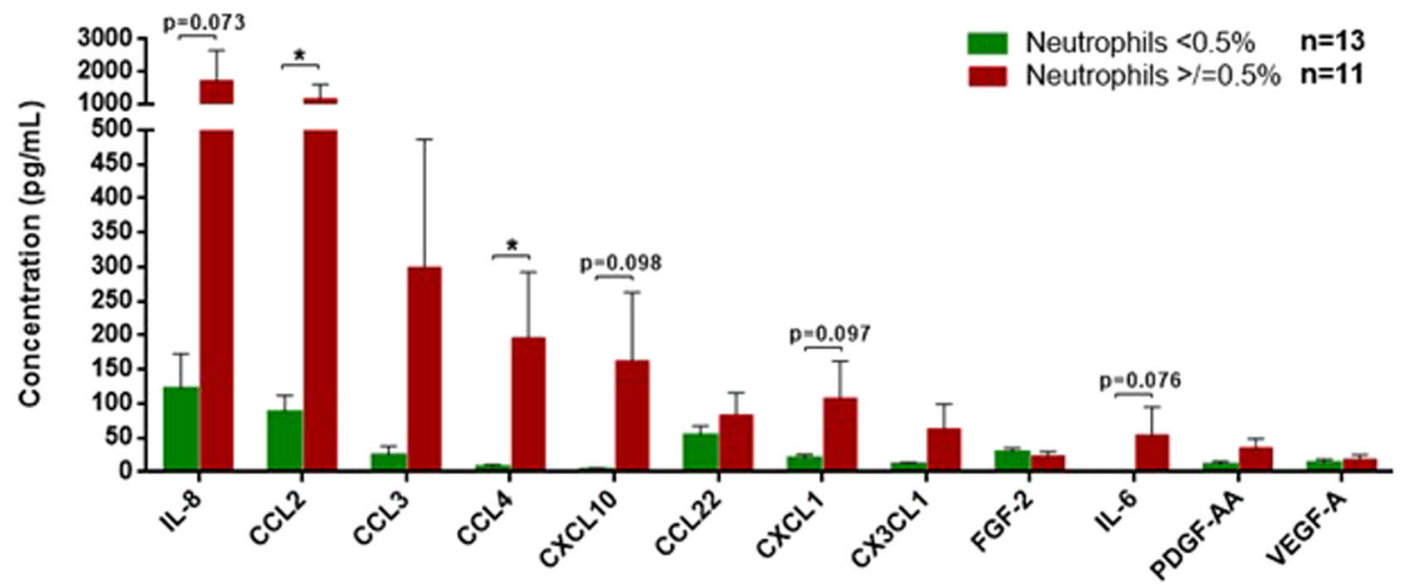

Fig. 4 Cytokine secretome of PitNETs cell culture supernatants with lower vs higher content of macrophages (a), CD8+ T cells (b) and neutrophils (c). The cutoffs used to define low and high immune cell content were: $6 \%$ for macrophages, $1 \%$ for CD8+ T cells and $0.5 \%$ for neutrophils. Data are shown for the top 12 secreted proteins as mean \pm standard error of the mean. ${ }^{*},<0.05$ (Mann Whitney $U$ test) 


\section{A) Immune cell infiltrates in PitNETs with low Ki-67 (<3\%) vs high Ki-67 ( $\geq 3 \%)$}

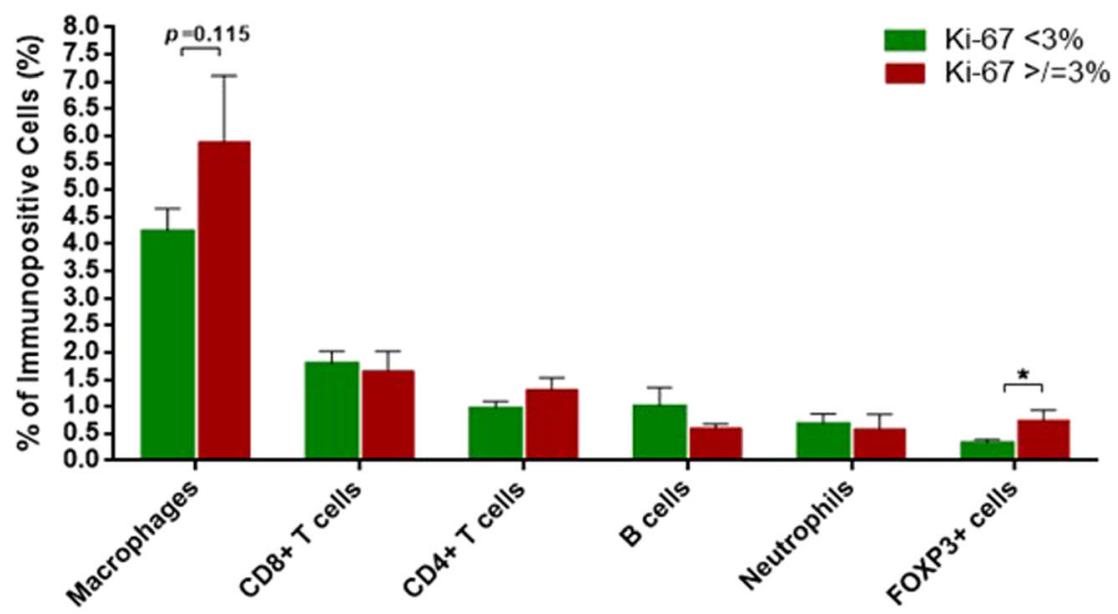

B) Immune cell ratios in PitNETs with low Ki-67 (<3\%) vs high Ki-67 ( $\geq 3 \%)$

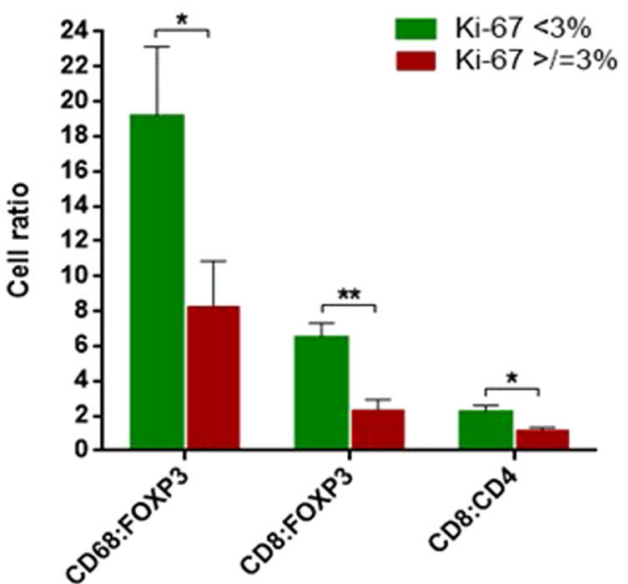

C)
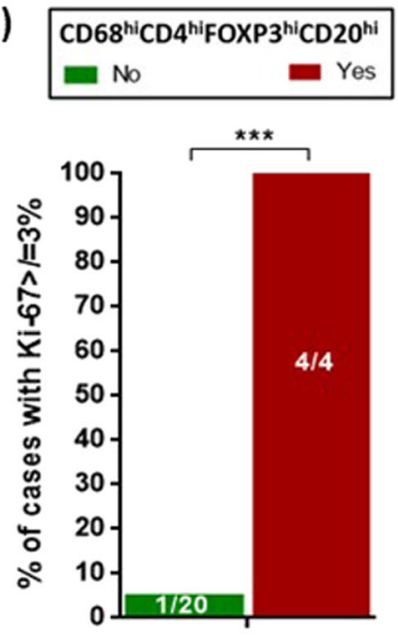

Fig. 5 Immune cell infiltrates (a) and immune cell ratios (b) in PitNETs with lower $(<3 \%)$ vs higher $(\geq 3 \%)$ Ki-67. PitNETs with lower Ki-67, $n=19$; PitNETs with higher Ki-67, $\mathrm{n}=5 .{ }^{*},<0.05,{ }^{* *},<0.01$ (Mann Whitney $\mathrm{U}$ test). c) Percentage of PitNETs with Ki-67 $\geq 3 \%$ according to the presence of a "deleterious immune infiltrate phenotype", i.e. higher content of macrophages, CD4+ T helper lymphocytes, FOXP3+ T regulatory cells and B cells (CD68 $\left.{ }^{\text {hi }} C D 4^{\text {hi }} F O X P 3^{\text {hi }} C D 20^{\text {hi }}\right)$. PitNETs with "deleterious immune infiltrate phenotype", $n=4$; PitNETs without "deleterious immune infiltrate phenotype", $n=20 .{ }^{* *},<0.001$ (Exact Fisher's test)

and macrophages (RAW 264.7 macrophage cell line), we established an in vitro model using $\mathrm{CM}$ from each of the cell line as a chemoattractant agent for the other. To investigate the role of GH3 cellderived factors in macrophage chemotaxis, we performed a transwell migration assay, observing a remarkable 36 -fold increase in macrophage migration towards GH3-CM in comparison to complete medium or recombinant CX3CL1 (Fig. 7a). CX3CL1 was used as positive control, as this was the chemokine with the highest concentration in GH3 supernatants (Additional file 7: Table S4), and has a recognised chemoattractant effect on RAW 264.7 macrophages [22]. Immune cell chemotaxis depends not only on tissue chemokine gradient, but also on chemokine receptor expression in trafficking cells [5]. GH3-CM increased more than $12 x$ the expression of CX3CR1 (receptor with specific affinity for CX3CL1 and highly expressed in RAW 264.7 macrophages [22]), as well as the expression of CCR5 ( $p=$ 0.051) (Fig. 7b). Thus, the GH3-CM macrophage chemoattractant effect can be explained, at least in part, by upregulation of chemokine receptor expression in RAW 264.7 macrophages. After GH3-CM treatment, macrophages showed morphological changes typical of activated macrophages: increase in cell area, perimeter, Feret's diameter and spindleshaped morphology $[42,44]$ and decrease in solidity, roundness and circularity (Fig. 7c), representing cells with enhanced migration phenotype. 


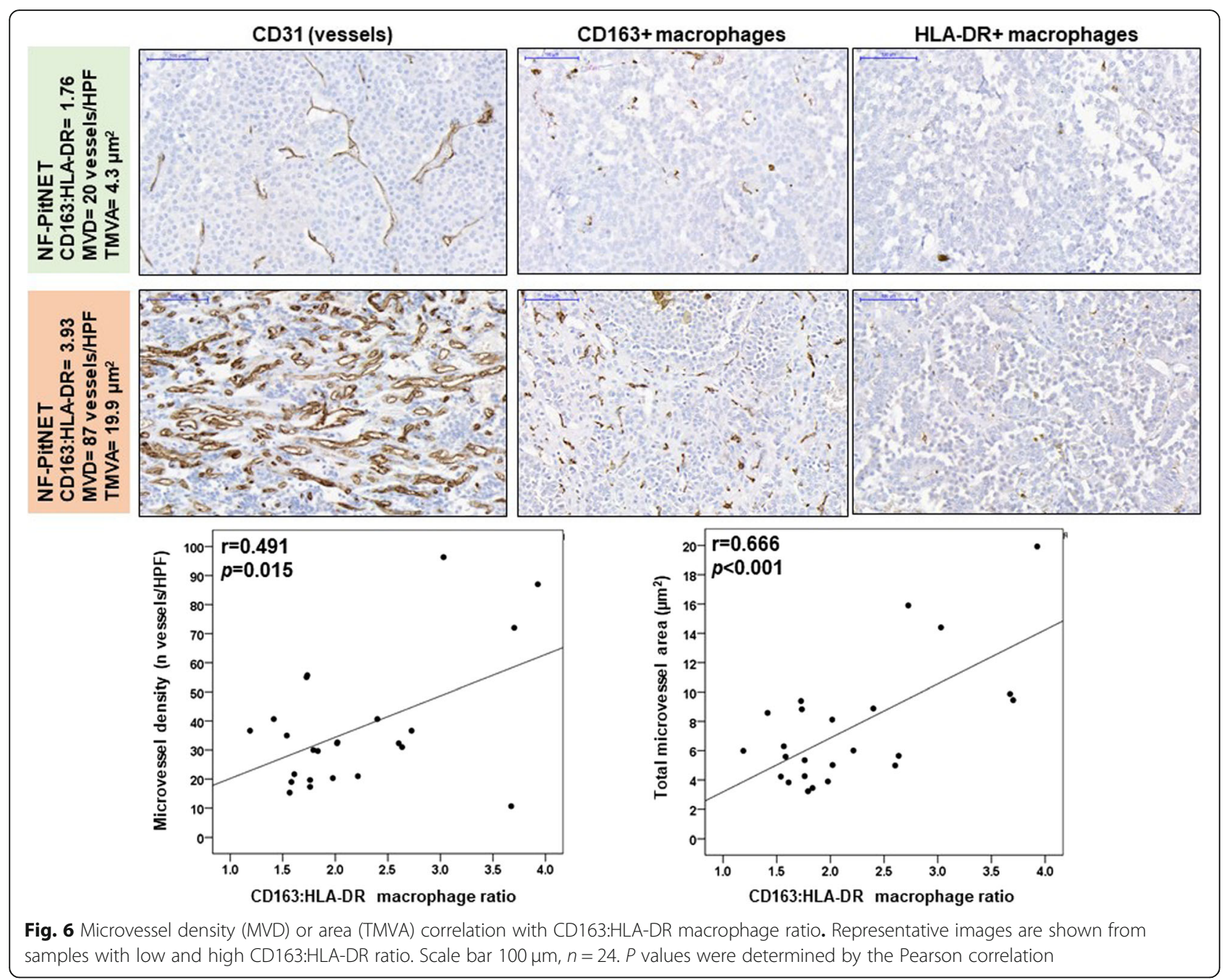

\section{Macrophage-derived factors affect the behaviour and invasiveness of $\mathrm{GH} 3$ cells}

RAW 264.7 macrophage-CM induced significant changes in GH3 cells: morphology changes, increased invasion, epithelial-to-mesenchymal transition (EMT) activation (Fig. 8) and alteration in cytokine secretion (Additional file 7: Table S4). Macrophage-CM from untreated (-PMA_ Raw.CM) or PMA-treated macrophages (+PMA_Raw.CM) increased GH3 cell area, perimeter and Feret's diameter, and reduced their solidity, roundness and circularity indicating that GH3 cells acquired an EMT-like phenotype. Macrophage-induced morphology changes in GH3 cells were confirmed with immunocytochemistry for actin: GH3 cells treated with macrophage-CM developed a granular pattern of actin with prominent stress fibres and numerous spikes (Fig. 8a), representing an EMT-like cytoskeletal alteration [50].

GH3 cells showed higher invasion towards +PMA_Raw$\mathrm{CM}$ compared to complete medium (Fig. 8b). As invasion depends on cell ability to secrete proteases to degrade extracellular matrix, we hypothesised that macrophage$\mathrm{CM}$ upregulates matrix metalloproteinases (MMPs) expression in GH3 cells allowing them to invade. MMP-9 is a key protease for type IV collagen degradation (main component of Matrigel [32], and of the pituitary capsule and cavernous sinus wall $[14,31,36])$, as well as MMP-9 overexpression is associated with PitNET invasiveness [36]. Hence, we studied MMP-9 expression in GH3 cells after treatment with macrophage-CM, and we observed a significant MMP-9 upregulation in GH3 cells exposed to macrophage-derived factors (Fig. 8c).

Macrophage-CM induced EMT activation in GH3 cells, decreasing E-cadherin and increasing ZEB1 expression (Fig. 8d), two hallmarks of EMT activation [17]. These findings are in line with the morphological changes and invasion assays results, suggesting that macrophagederived factors interact with pituitary tumour cells influencing their behaviour and invasiveness.

We also found that PMA-activated macrophage-CM induced cytokine secretion changes in GH3 cells, 


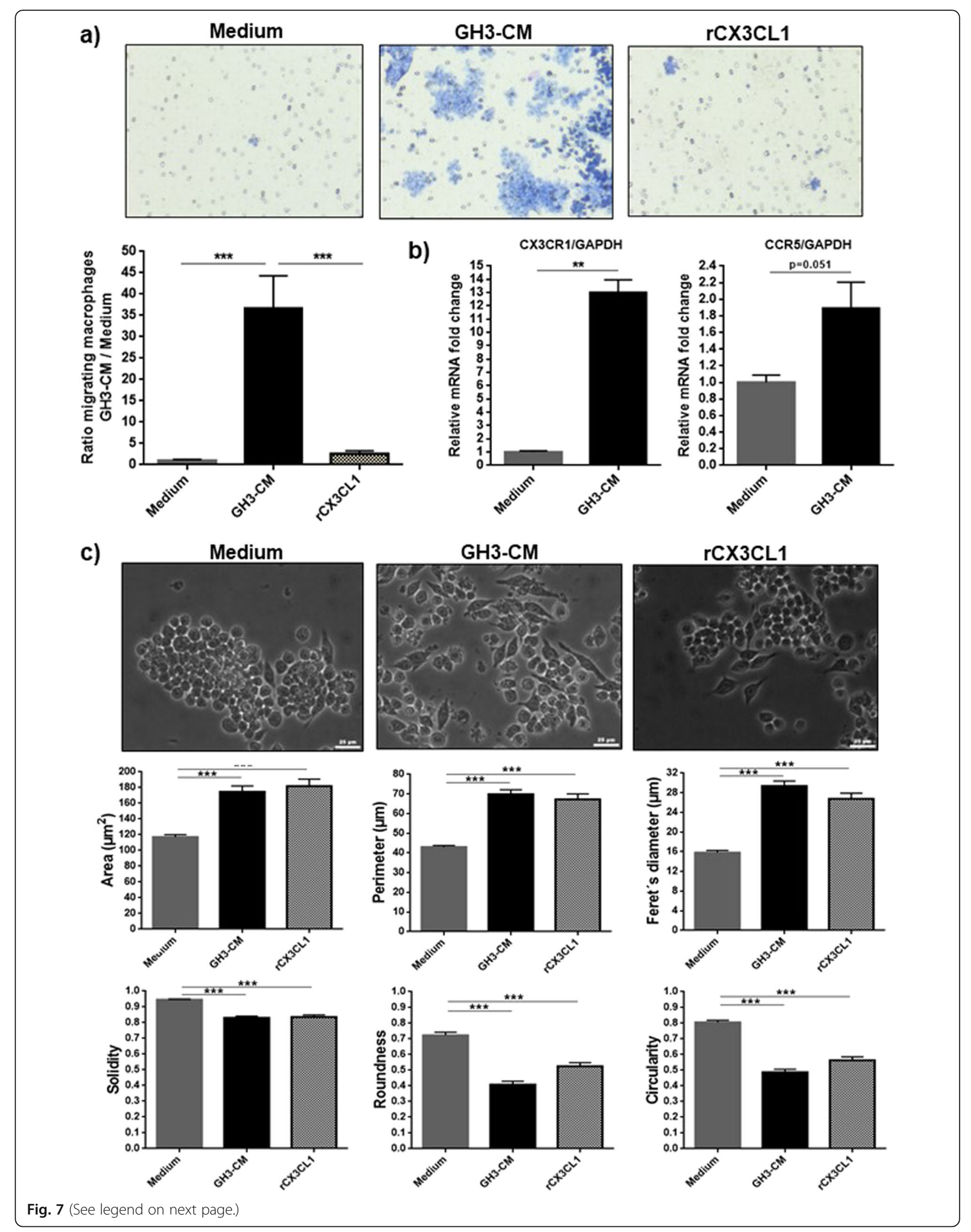


(See figure on previous page.)

Fig. 7 a Transwell chemotaxis assay performed on RAW 264.7 macrophages towards complete medium, GH3-CM and recombinant CX3CL1 ( $\mathrm{CXX3CL1)}$ at concentration $100 \mathrm{ng} / \mathrm{mL}$ for $72 \mathrm{~h}$. Data are shown as mean \pm standard error of the mean (SEM) for the ratio of migrated RAW 264.7 macrophages towards GH3-CM or rCX3CL1 in relation to migrated macrophages in complete medium. $n=6 .{ }^{* * *},<0.001$ (one way-ANOVA with Bonferroni multiple comparison test). b CX3CR1 and CCR5 expression in RAW 264.7 macrophages determined by RT-qPCR after treatment with GH3-CM for $24 \mathrm{~h}$ vs complete medium. Data are shown as mean \pm SEM for CX3CR1 or CCR5 relative fold change expression to GAPDH, determined by the $\Delta \Delta C T$ method. $n=3$. ${ }^{* *},<0.01$ (Mann Whitney $\mathrm{U}$ test). c Morphological evaluation of RAW 264.7 macrophages after treatment for $72 \mathrm{~h}$ with complete medium $(n=3), \mathrm{GH} 3-\mathrm{CM}$ and $\mathrm{rCX} 3 \mathrm{CL} 1$ at concentration of $100 \mathrm{ng} / \mathrm{mL}$. Data are shown as mean \pm SEM for the 6 morphological parameters evaluated by Image J: cell area $\left(\mu \mathrm{m}^{2}\right)$, Feret's diameter $(\mu \mathrm{m})$, solidity $(0-1)$, perimeter $(\mu \mathrm{m})$, roundness $(0-1)$ and circularity (0-1). Per experiment 75 cells were analysed, with a minimum of 3 experiments per treatment condition. Scale bar $25 \mu \mathrm{m} .{ }^{* * *},<0.001$ (one-way ANOVA with Bonferroni multiple comparison test)

increasing the release of CX3CL1, CCL3, CXCL1, CXCL10, IL-1ß, IL-10, IL-13 and VEGF (Additional file 7: Table S4), peptides that play a role in different tumourigenic mechanisms [5, 7, 40, 41].

\section{Discussion}

In this study, we found that PitNETs are an active source of cytokines, particularly chemokines, which facilitate macrophage, neutrophil and lymphocyte recruitment into the TME. We found increased macrophage content in the tumours, which together with the other cells provide an inflammatory signature correlating with Ki-67 staining. Our in vitro cell model data confirmed the macrophage chemoattractant effect of pituitary tumour-derived factors, while macrophage-derived factors influence tumour cell behaviour leading to morphological changes, increased invasion, cytokine secretome changes and EMT activation. Thus, the cytokine network within the TME of PitNETs, derived from both tumour and immune cells, as well as from PitNET-associated fibroblasts [47], may play a role in the modulation of the TME and in the aggressiveness of PitNETs (Fig. 9).

IL-8, CCL2, CCL3 and CCL4 were highly secreted by the majority of PitNETs. Cytokine array data from human craniopharyngiomas identified CCL2 and IL-8 as the most secreted cytokines in plasma, primary culture supernatants, cell and tissue lysates [57]. There are no previous data on CCL2, CCL3 or CCL4 in PitNETs, but these chemokines are involved in tumour growth and invasion in other tumours $[5,41]$, as well as in immune cell chemotaxis in cancer $[5,12,16,41,43,63,72,92]$. We found no association between CCL2, CCL3 or CCL4 levels and PitNET aggressiveness, but PitNETs with a higher content of macrophages, CD8+ $\mathrm{T}$ cells and neutrophils secreted higher chemokine levels. PitNETs with more macrophages were associated with higher levels of IL-8, a chemokine that influences several oncogenic pathways [1, 86]. IL-8 mRNA was previously found in PitNETs, although different detection methods provided a wide range of expression levels [23, 76, 84]. We also identified other chemokines potentially relevant in PitNETs, namely CXCL10, CCL22, CXCL1 and CX3CL1. Our data suggest CXCL1 and CXCL10 as potential modulators of PitNET- infiltrating neutrophils and macrophages. CXCL1 and its receptor CXCR2 were previously identified in human PitNETs [79], but there are no data regarding CXCL10, CCL22 and CX3CL1. Together, these findings suggest a link between endocrine cells and chemokines reflecting their possible involvement in tumourigenesis and modulation of immune infiltrates, as well as a promising target for drugs affecting the PitNET cytokine network, as already explored for other cancers [7, 41, 67].

Macrophages are present in normal $[29,39]$ and neoplastic pituitary [10, 21, 37]. Our immunohistochemical and $x$ CELL data showed that PitNETs contained 3-4x more macrophages than NPs, and are the predominant immune cell type in PitNETs. We found no association between PitNET-infiltrating macrophages and cavernous sinus invasion, and the correlation with high Ki-67 was borderline. $\mathrm{Lu}$ et al. reported that macrophage content was correlated with size and invasiveness [37]. AIP mutation-positive somatotropinomas, often more aggressive $[45,46]$, have more PitNETs-infiltrating macrophages than sporadic somatotropinomas or NPs [10].

Next, we studied the phenotype of infiltrating macrophages in human PitNETs and NPs using CD163 (M2-like) and HLA-DR (M1-like) macrophage markers [44, 71, 81]. We noted a 3-fold increased CD163:HLA-DR ratio in PitNETs compared to NPs, in line with our xCell data (score for M2-macrophages was $>4 \mathrm{x}$ higher in PitNETs). The predominance of M2-macrophages in PitNETs can be due, at least in part, to higher concentrations of PitNET-derived M2-polarising cytokines, namely IL-4, which was $\sim 5 \mathrm{x}$ higher than IFN $\gamma$, the main M1-polarising cytokine [42, 44]. M1- and M2-like macrophages have been described in normal rat pituitary and in diethylstilbestrol-induced prolactinomas [21], with prolactinomas having remarkably more M2-macrophages than NP. M2-macrophages number increased during the first weeks of diethylstilbestrol treatment, even before tumour formation, suggesting a role for M2-macrophages in initiating tumourigenesis. During diethylstilbestrol treatment capillaries became more tortuous with increased calibre and developed haemorrhage areas, suggesting a possible role for M2-macrophages in angiogenesis and vasculature modulation in PitNETs [21], in agreement with our observed correlations between CD163: 
a) Morphology study
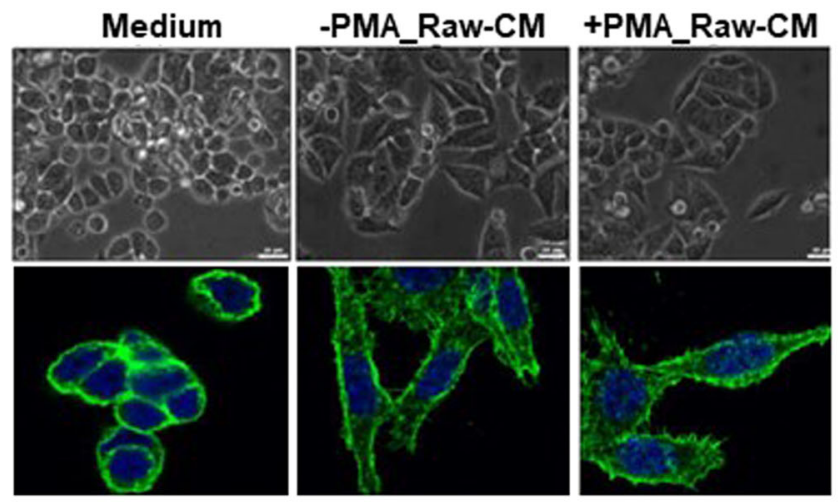

b) Matrigel invasion assay

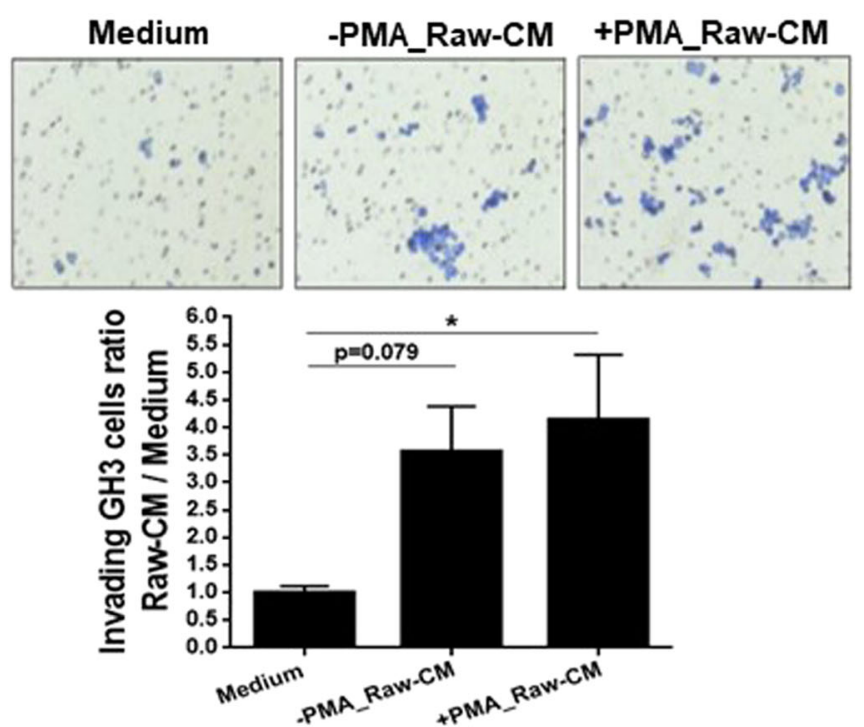

d) E-cadherin and ZEB1 immunofluorescence studies
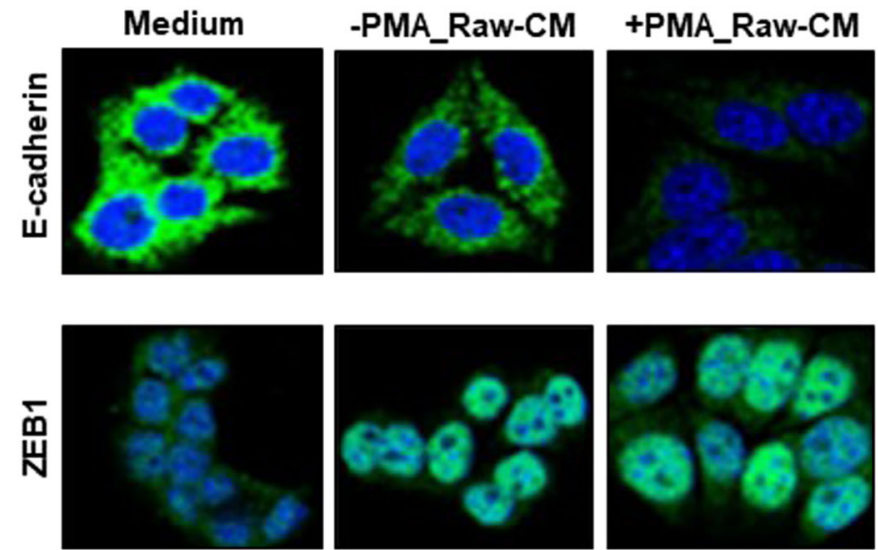
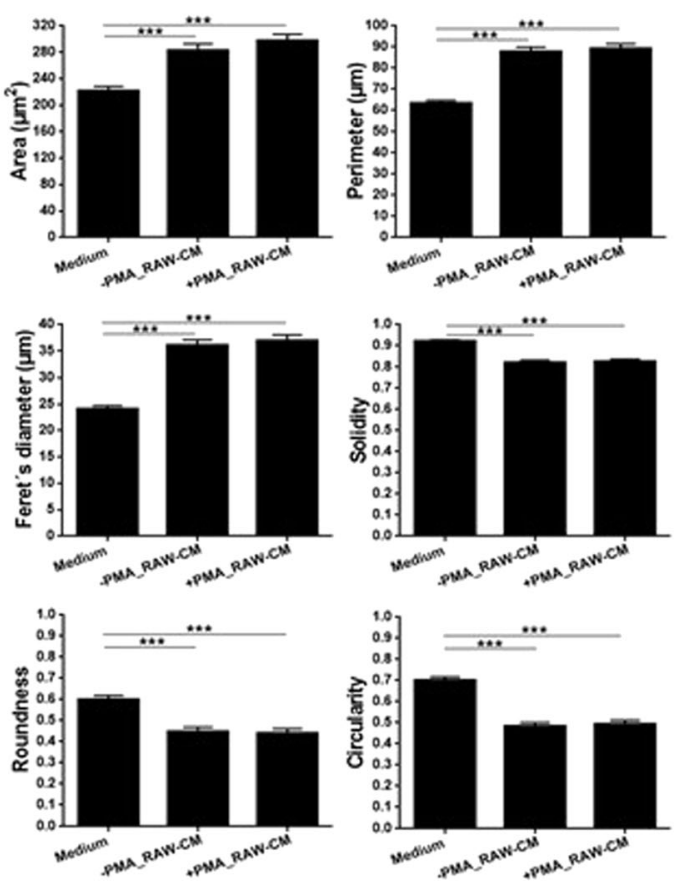

C) MMP9/GAPDH mRNA expression
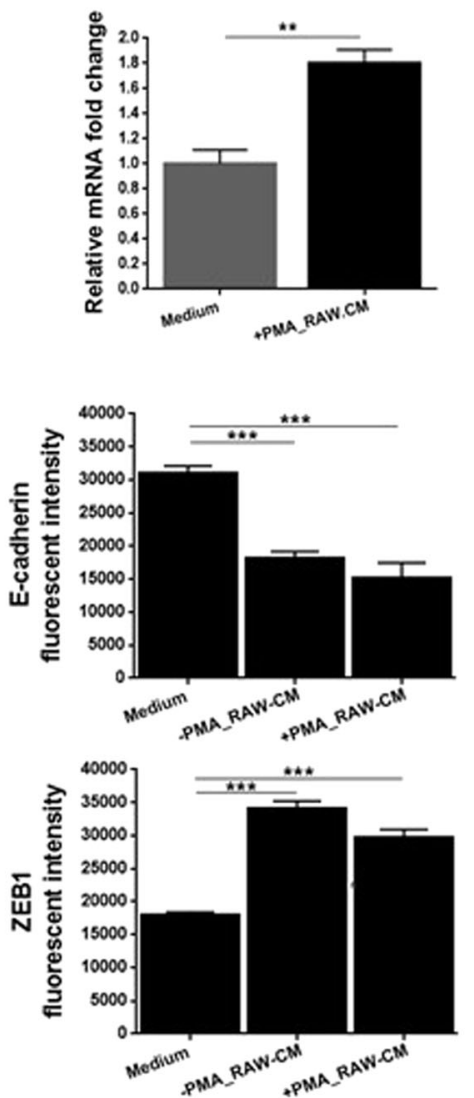

Fig. 8 (See legend on next page.) 
(See figure on previous page.)

Fig. 8 a Morphological evaluation of GH3 cells after treatment for $72 \mathrm{~h}$ with complete medium and RAW 264.7 macrophage-CM, either from untreated macrophages (-PMA_Raw.CM) or macrophages treated with PMA (+PMA_Raw.CM). Data are shown as mean \pm standard error of the mean (SEM) for the 6 morphological parameters evaluated by Image J: cell area $\left(\mu \mathrm{m}^{2}\right)$, Feret's diameter $(\mu \mathrm{m})$, solidity $(0-1)$, perimeter $(\mu \mathrm{m})$, roundness (0-1) and circularity (0-1). Seventy-five cells were analysed per experiment, with a minimum of 3 experiments per treatment condition. Scale bar $25 \mu \mathrm{m} .{ }^{* *},<0.001$ (one-way ANOVA with Bonferroni multiple comparison test). Alterations on actin cytoskeletal fibers in GH3 cells after treatment with macrophage-CM for $72 \mathrm{~h}$ in comparison to complete medium; representative images taken on confocal microscope at $63 \mathrm{x}$ magnification; DAPI was used to stain the nuclei. b Matrigel-coated chamber invasion assays on GH3 cells towards complete medium, -PMA_Raw.CM and + PMA_Raw.CM after $72 \mathrm{~h}$. Data are shown as mean \pm SEM for the ratio of invading GH3 cells towards -PMA_Raw.CM and + PMA_Raw.CM in relation to invading GH3 cells in complete medium conditions. Invasion studies were repeated 4 times in duplicate. *, $<0.05$ (one-way ANOVA with Bonferroni multiple comparison test). c MMP-9 expression in GH3 cells in complete medium or after treatment for $24 \mathrm{~h}$ with + PMA_Raw.CM, as determined by RT-qPCR. Data are shown mean \pm SEM for the relative MMP9 mRNA fold change expression to GAPDH, as determined by the $\triangle \triangle C T$ method. $\mathrm{n}=3 .{ }^{*}{ }^{*},<0.01$ (Mann Whitney $\mathrm{U}$ test). $\mathbf{d}$ Alterations in E-cadherin and ZEB1 expression by GH3 cells after $72 \mathrm{~h}$ treatment with complete medium, -PMA_Raw.CM or + PMA_Raw.CM. Untreated GH3 cells show strong E-cadherin with membranous localisation but also in the cytoplasm as well as low nuclear ZEB1 expression, while macrophage-CM treated GH3 cells display decreased E-cadherin expression and increased nuclear ZEB1 expression. Pictures were taken on confocal microscope at 63x magnification. DAPI was used to stain the nuclei. E-cadherin and ZEB1 fluorescent intensities are shown as mean \pm SEM and were quantified in 30 different cells per treatment condition. ***, $<0.001$ (one-way ANOVA with Bonferroni multiple comparison test)

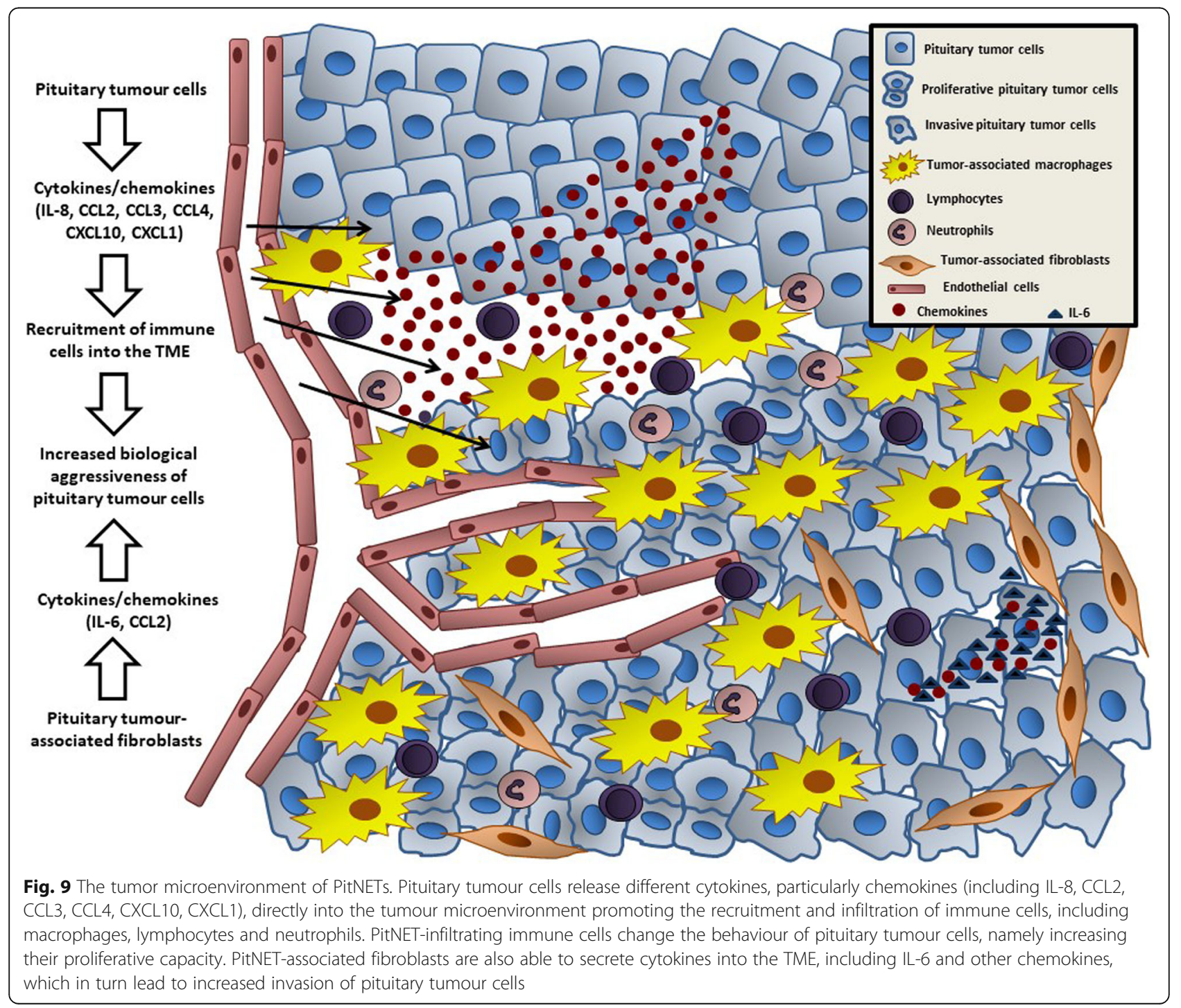


HLA-DR macrophage ratio and PitNET microvessel density and area. These findings support a role for infiltrating M2macrophages in the angiogenesis of PitNETs, as previously described in other cancers [13, 27, 42, 44, 80, 83]. We found no association between PitNET-infiltrating CD163+ macrophages and cavernous sinus invasion, although a recent study showed more CD163+ macrophages in invasive NFPitNETs than in non-invasive tumours [68].

We found that a low CD8:CD4 ratio is associated with higher $\mathrm{Ki}-67$, suggesting that relatively low $\mathrm{CD} 8+$ to high CD4+ T cells, rather than absolute CD8+ and CD4+ T cell amounts per se, represent a relative imbalance potentially affecting tumour proliferation. This has been previously described in gliomas, where the number of tumourinfiltrating $\mathrm{CD} 8+$ and $\mathrm{CD} 4+$ cells alone had no prognostic value, while the presence of a low CD8:CD4 ratio was an independent predictor for poor progression-free and overall survival [26]. Poor clinical outcome and persistence/recurrence was described in PitNETs with tumour-infiltrating lymphocytes [38]. Another study found no association between CD8+ T cell count and Ki-67, tumour size, gender or age [85]. We observed more CD4+ and fewer CD8+ cells, with a significant 2-fold decrease in CD8:CD4 ratio in comparison to NPs, supporting the known anti-tumoural role of cytotoxic CD8+ T cells and the pro-tumoural CD4+ $\mathrm{T}$ cells, possibly Th2 $[9,25,26]$. Indeed, downregulation of Th1 pathway-related genes was observed in aggressive PitNETs [64]. CD163+ macrophages, the predominant form we observed in PitNETs, support CD4+ Th2 cells and prevent the expression of cytokines required for CD4+ Th1 cells $[37,54]$, which may further contribute to a PitNETassociated Th2 phenotype. Visa versa, CD4+ Th2 cytokines in the TME sustain M2 macrophages [43, 44, 54] possibly contributing to the CD163+ macrophage phenotype we observed in PitNETs.

Although we found generally low amounts of FOXP3+ $\mathrm{T}$ cells in PitNETs, as previously shown [30], PitNETs with higher Ki-67 had significantly more FOXP3+ T cells. Moreover, a significant 3-fold reduced CD8:FOXP3 ratio was noted in PitNETs with a higher Ki-67, revealing that a deleterious imbalance between CD8+ and FOXP3+ T cells may lead to increased proliferation and thereby aggressiveness, as described for other cancers [70, 77]. In our study, all PitNETs with a "deleterious immune phenotype", i.e. higher content of macrophages, $\mathrm{T}$ helper lymphocytes, FOXP3 + T regulatory and B cells, had a Ki-67 $\geq$ $3 \%$, which together with results regarding cell ratios CD68:FOXP3, CD8:CD4 and CD8:FOXP3, highlights that the pooled inflammatory context integrating different immune subpopulations within the TME of PitNETs is more relevant for biological behaviour and aggressiveness than each PitNET-infiltrating immune cell per se.

We found significantly less neutrophils in PitNETs than NPs. Somatotropinomas had fewer neutrophils than
NF-PitNETs which could be due to less chemokine release, particularly IL-8, as suggested by our data, but other factors can be also involved such as impaired neutrophil chemotaxis in acromegaly [20].

There is some variability in the PitNETs immune infiltrates reported in the literature [28, 37, 38, 52, 65, 85]. This variability can reflect the variable level of immunosurveillance from tumour to tumour $[9,74,75]$, patient selection [37], or can be due to lack of standardisation method reporting immune infiltrates [37, 38, 85], such as reporting hot spots or taking random HPFs, or reporting interstitial areas or perivascular inflammatory cells [37], usage of different cell markers and antibodies to detect the same immune cell type $[28,37,38]$, or assessment of full slides versus tissue microarrays, which can all greatly influence the results. Despite these issues, our immunohistochemical data are in agreement with our xCELL data, and are generally in line with the previously published data $[37,38,52,85]$.

Our in vitro cell line experiments focused on macrophages as these are the predominant immune cell type in PitNETs, and we selected RAW 264.7 macrophages for a number of reasons: (i) lack of a reliable rat macrophage cell line; (ii) high homology between mouse and rat cytokines; (iii) expression of CX3CR1 [22], the chemokine receptor for CX3CL1 which was the main GH3 cell-derived chemokine according to our cytokine array data and (iv) to validate some of our previous observations on a different cell model employing primary bonemarrow derived rat macrophages and GH3 cells [10]. Our in vitro observations here reported, consistent with our previous findings on a different cell model [10], show a remarkable macrophage chemoattractant effect induced by GH3 cell-derived factors, an effect explained not only by the chemokine gradient but also by their ability to upregulate chemokine receptor expression. These findings are in line with our human data (association between PitNET-infiltrating macrophages and higher PitNET-derived chemokine levels), suggesting that PitNET cells could attract macrophages. In turn, we showed that macrophage-derived factors induced numerous effects on GH3 cells, including changes in morphology, invasion, EMT activation and cytokine secretome alterations, suggesting that immune cellderived factors influence tumour mechanisms and lead to increased PitNET aggressiveness, as shown in other cancers $[5,7,40,41]$.

Our study, using a comprehensively phenotyped cohort of human samples with cytokine array data from primary culture, immunohistochemical immune cell infiltrates and clinicopathological data, found an association between PitNET-derived chemokines and infiltrating immune cells, particularly macrophages, CD8+ $\mathrm{T}$ cells and neutrophils. These data suggest a potential role for immune infiltrates 
to determine PitNET aggressiveness, particularly proliferation. Our human data are strengthened by our in vitro functional data providing mechanistic insights into the crosstalk between pituitary tumour cells and macrophages.

Limitations of our study include the fact that we have a relatively small cohort of cases, and thus our observations need to be validated in larger series preferably including all different PitNET types. As the study is based on fresh primary culture, we inevitably have a relatively short postoperative follow-up of the patients, rendering data on recurrence unavailable. In our in vitro data we used a rat rather than human cell line, as a human pituitary cell line does not exist; moreover, our monolayer cell cultures are unable to investigate the complex paracrine and autocrine interactions occurring in vivo within the TME, which involves a wider range of immune cells besides macrophages, as well as stromal cells, endothelial cells, pericytes and the extracellular matrix [6]. We followed a CD163+ and HLA-DR+ distinction between macrophages [27, 42, 44], although we acknowledge that is simplistic and may not comprehensively address the heterogeneous and complex macrophage phenotypes representing the wide spectrum of macrophages [55]. There is a considerable heterogeneity on methodology used to study tumour-associated macrophages, particularly regarding their surface markers. We selected CD68 which satisfactorily identify general macrophages, and CD163 to identify alternatively activated macrophages [27, 42, 44]. Studying classically activated macrophages is more challenging, as a specific marker is lacking, but HLA-DR or iNOS (inducible nitric oxide synthase) are often used for this purpose [34, 44, 51]. Thus, our findings from the immunohistochemical study may well be partially influenced by such elements; nevertheless, our data were reproduced on a separate set of samples using a different methodology (the gene-signature based $x$ Cell), providing another layer of evidence regarding the macrophage phenotype of human PitNETs.

\section{Conclusions}

Our data suggest that pituitary tumour cells release cytokines, particularly chemokines, which facilitate immune cell recruitment into the tumour microenvironment of PitNETs. The increased inflammatory signature could influence tumour cell proliferation. We found increased macrophage migration towards pituitary tumour cell-derived factors in vitro, and in turn, macrophage secreting-factors change pituitary cells phenotype inducing epithelial-to-mesenchymal transition, increased invasion and altered cytokine secretion. Our study provide novel insights into the PitNET biology, and provide novel targets for treatment of aggressive PitNETs.

\section{Supplementary information}

Supplementary information accompanies this paper at https://doi.org/10. 1186/s40478-019-0830-3.

\section{Additional file 1: Figure S1. a) Cytokine secretome from}

somatotropinomas treated pre-operatively with somatostatin analogues (Pre-op SSA, $n=5$ ) vs not treated (No pre-op SSA, $n=3$ ). b) Cytokine secretome from densely granulated $(n=3)$ vs sparsely granulated $(n=5)$ somatotropinomas. Data are shown for the top 12 secreted proteins as mean concentration \pm standard error of the mean. No significant differences were found (Mann Whitney $U$ test).

Additional file 2: Figure S2. xCELL Fraction Scores obtained from microarray expression data from a different set of samples (7 PitNETs - 4 NF-PitNETs and 3 somatotropinomas - and 5 NPs). Data are shown in mean xCELL Fraction Score \pm standard error of the mean. Comparative analysis was carried out for the immune cell types originally analysed by immunohistochemistry in our cohort. ${ }^{*},<0.05,{ }^{* *},<0.01,{ }^{* * *},<0.001$ (Mann Whitney $U$ test).

Additional file 3: Figure S3. Correlation between PitNET tissue immune cell infiltrates and the respective circulating immune cell subpopulation. $n=24$. $P$ values were determined by the Pearson correlation.

Additional file 4: Table S1. Primary antibodies and respective dilutions used for immunohistochemical $(\mathrm{IHC})$ and immunofluorescence (IF) studies.

Additional file 5: Table S2. Cytokine secretome from the 24 human PitNETs-derived cell culture supernatants. PitNETs-derived supernatants were collected at $24 \mathrm{~h}$ on serum-free medium conditions and cytokine secretome determined with the human Millipore MILLIPLEX cytokine 42plex array. Data are shown as mean concentration $(\mathrm{pg} / \mathrm{mL}) \pm$ standard error of the mean (SEM) for all detectable cytokines/ chemokines/ growth factors. IL-1 ra, IL-2, IL-3, IL-5, IL-7, IL-9, IL-13, CCL7, sCD40L, TNF- $\beta$ and TGF-a were undetectable in PitNETs-derived supernatants.

Additional file 6: Table S3. Immunohistochemical analysis of the immune cells and respective ratios among the various NF-PitNET types, and subgroup comparative analysis between NF-PitNETs vs somatotropinomas. Immune cells analysed: macrophages (CD68+), CD163+ macrophages, HLA-DR macrophages, cytotoxic T lymphocytes (CD8+), T helper lymphocytes (CD4+), T regulatory cells (FOXP3+), B cells (CD20+) and neutrophils (neutrophil elastase + ). Data are shown as mean \pm standard error of the mean for percentage of immune cells compared to the total number of tumour cells and for cell ratios. One way-ANOVA test was used to calculate $p$ value among the NF-PitNETs histiotypes: gonadotroph PitNET, silent corticotroph PitNET and null cell PitNET (GP vs SCP vs NCP). Mann Whitney $U$ test was used to calculate $p$ value for the comparison NF-PitNETs vs somatotropinomas (NF vs Som).

Additional file 7: Table S4. Cytokine secretome from GH3 cells at baseline (untreated) and after treatment with PMA-activated RAW 264.7 macrophage-CM (+PMA_Raw-CM) for $24 \mathrm{~h}(n=3)$. Data are shown in concentration $(\mathrm{pg} / \mathrm{mL}) \pm$ standard error of the mean (SEM) for the cytokines/chemokines/growth factors with detectable concentrations as identified by the rat Millipore MILLIPLEX cytokine 27-plex array. CCL5, CCL11, G-CSF, GM-CSF, IL-1a, IL-12, IL-17A, TNF-a, EGF, Leptin and LIX were not detected in the $\mathrm{GH} 3$ supernatants (i.e. concentration below the lowest standard curve point and/or serum-free medium quantification). Mean ratio \pm SEM between untreated vs + PMA_Raw-CM GH3 cells-treated is also shown in the table, with significant $p$ values indicated in the same column as asterisks. ${ }^{*},<0.05,{ }^{* *},<0.01$ (Mann Whitney $U$ test).

\section{Abbreviations}

CM: Conditioned medium; CT: Cycle threshold; DMEM: Dulbecco's Modified Eagle's Medium; EMT: Epithelial-to-mesenchymal transition; FBS: Foetal bovine serum; HPF: High power field; iNOS: Inducible nitric oxide synthase; MMP: Matrix metalloproteinase; NF-PitNET: Non-functioning pituitary neuroendocrine tumour; NP: Normal pituitary; PBS: Phosphate Buffered Saline; PitNET: Pituitary neuroendocrine tumour; PMA: Phorbol 12-Myristate 13-Acetate; RT-qPCR: Real-time quantitative polymerase chain reaction; TME: Tumour microenvironment 


\section{Acknowledgments}

We are grateful to Edwin Garcia (William Harvey Research Institute, Queen Mary University of London, UK) for the skillful technical assistance with the pituitary neuroendocrine tumour primary cultures. We indebted to Federico Roncaroli (Manchester, UK) for the critical review of this manuscript. We acknowledge the expert care of colleagues involved in the care of the patients participating in the study, including endocrinologists (Stephanie Baldeweg, University College Hospital, London, UK, William M. Drake and Scott A. Akker, St. Bartholomew's Hospital, London, UK), neuropathologists (Sebastian Brander, Institute of Neurology, London, UK), neuroradiologists (Jane Evanson, St. Bartholomew's Hospital, London, UK), and pituitary nurse specialist (Marianna Shiafkou, St. Bartholomew's Hospital, London, UK). We are grateful to the patients involved in the study.

\section{Authors' contributions}

PM has designed and performed the study, analysed the data and written the manuscript; SB helped with in vitro experiments and conducted the Affymetrix microarray analysis; EC scored the immunohistochemistry sections; DC and AR assisted with obtaining informed consent from patients, samples collection and clinical data retrieval; SA assisted with microarray data xCell deconvolution; ND, JG, NM, SM provided the specimens for primary culture and immunohistochemistry studies and provided critical input; ABG provided critical input; MK designed the study and written the manuscript. All authors read and approved the final manuscript.

\section{Funding}

P.M. was supported by the Joan Adams Clinical Fellowship and the Barts and The London Charity Clinical Research Training Fellowship. M.K. had Medical Research Council (UK) funding to support to study familial isolated pituitary adenomas.

\section{Availability of data and materials}

Microarray data used for xCell analysis have been deposited with the National Center for Biotechnology Information Gene Expression Omnibus (www.ncbi.nlm.nih.gov/geo, accession number GSE63357).

\section{Ethics approval and consent to participate}

This study was approved by the Medical Research Ethics Committee (MREC No. 06/Q0104/133). All patients gave written informed consent.

\section{Consent for publication}

Not applicable.

\section{Competing interests}

The authors declare that they have no competing interests.

\section{Author details}

${ }^{1}$ Centre for Endocrinology, William Harvey Research Institute, Barts and the London School of Medicine and Dentistry, Queen Mary University of London, London, UK. ${ }^{2}$ Department of Pathology, STHF, Skien, Norway. ${ }^{3}$ The National Hospital for Neurology and Neurosurgery, UCLH, NHS Trust, London, UK. ${ }^{4}$ Department of Neurosurgery, Charing Cross Hospital, Imperial College, London, UK. ${ }^{5}$ Department of Neurosurgery, Derriford Hospital, Plymouth, UK. ${ }^{6}$ Barts Cancer Institute, Barts and the London School of Medicine and Dentistry, Queen Mary University of London, Charterhouse Square, London, UK.

Received: 28 August 2019 Accepted: 13 October 2019

Published online: 08 November 2019

\section{References}

1. Alfaro C, Sanmamed MF, Rodriguez-Ruiz ME, Teijeira A, Onate C, Gonzalez A, Ponz M, Schalper KA, Perez-Gracia JL, Melero I (2017) Interleukin-8 in cancer pathogenesis, treatment and follow-up. Cancer Treat Rev 60:24-31. https:// doi.org/10.1016/j.ctrv.2017.08.004

2. Aran D, Hu Z, Butte AJ (2017) xCell: digitally portraying the tissue cellular heterogeneity landscape. Genome Biol 18:220. https://doi.org/10.1186/ s13059-017-1349-1

3. Asa SL, Casar-Borota O, Chanson P, Delgrange E, Earls P, Ezzat S, Grossman A, Ikeda H, Inoshita N, Karavitaki N, Korbonits M, Laws ER Jr, Lopes MB, Maartens N, IE MC, Mete O, Nishioka H, Raverot G, Roncaroli F, Saeger W,
Syro LV, Vasiljevic A, Villa C, Wierinckx A, Trouillas J, attendees of 14th Meeting of the International Pituitary Pathology Club AFN (2017) From pituitary adenoma to pituitary neuroendocrine tumor (PitNET): an International Pituitary Pathology Club proposal. Endocr Relat Cancer 24:C5C8. https://doi.org/10.1530/ERC-17-0004

4. Balkwill F, Montfort A, Capasso M (2013) B regulatory cells in cancer. Trends Immunol 34:169-173. https://doi.org/10.1016/j.it.2012.10.007

5. Balkwill FR (2012) The chemokine system and cancer. J Pathol 226:148-157. https://doi.org/10.1002/path.3029

6. Balkwill FR, Capasso M, Hagemann T (2012) The tumor microenvironment at a glance. J Cell Sci 125:5591-5596. https://doi.org/10.1242/jcs.116392

7. Balkwill FR, Mantovani A (2012) Cancer-related inflammation: common themes and therapeutic opportunities. Semin Cancer Biol 22:33-40. https:// doi.org/10.1016/j.semcancer.2011.12.005

8. Barbieri F, Bajetto A, Stumm R, Pattarozzi A, Porcile C, Zona G, Dorcaratto A, Ravetti JL, Minuto F, Spaziante R, Schettini G, Ferone D, Florio T (2008) Overexpression of stromal cell-derived factor 1 and its receptor CXCR4 induces autocrine/paracrine cell proliferation in human pituitary adenomas. Clin Cancer Res 14:5022-5032. https://doi.org/10.1158/1078-0432.CCR-07-4717

9. Barnes TA, Amir E (2017) HYPE or HOPE: the prognostic value of infiltrating immune cells in cancer. Br J Cancer 117:451-460. https://doi.org/10.1038/ bjc.2017.220

10. Barry S, Carlsen E, Marques P, Stiles CE, Gadaleta E, Berney DM, Roncaroli F, Chelala C, Solomou A, Herincs M, Caimari F, Grossman AB, Crnogorac-Jurcevic T, Haworth O, Gaston-Massuet C, Korbonits M (2019) Tumor microenvironment defines the invasive phenotype of AIP-mutation-positive pituitary tumors. Oncogene 38:5381-5395. https://doi.org/10.1038/s41388-019-0779-5

11. Bissell MJ, Radisky D (2001) Putting tumours in context. Nat Rev Cancer 1: 46-54. https://doi.org/10.1038/35094059

12. Brown CE, Vishwanath RP, Aguilar B, Starr R, Najbauer J, Aboody KS, Jensen MC (2007) Tumor-derived chemokine MCP-1/CCL2 is sufficient for mediating tumor tropism of adoptively transferred T cells. J Immunol 179: 3332-3341

13. Carmeliet P, Jain RK (2011) Molecular mechanisms and clinical applications of angiogenesis. Nature 473:298-307. https://doi.org/10.1038/nature10144

14. Ceylan S, Anik I, Koc K, Kokturk S, Ceylan S, Cine N, Savli H, Sirin G, Sam B, Gazioglu $\mathrm{N}$ (2011) Microsurgical anatomy of membranous layers of the pituitary gland and the expression of extracellular matrix collagenous proteins. Acta Neurochir 153: 2435-2443; discussion 2443. https://doi.org/10.1007/s00701-011-1182-3

15. Chatzellis E, Alexandraki Kl, Androulakis II, Kaltsas G (2015) Aggressive pituitary tumors. Neuroendocrinology 101:87-104. https://doi.org/10.1159/ 000371806

16. Coffelt SB, Wellenstein MD, de Visser KE (2016) Neutrophils in cancer: neutral no more. Nat Rev Cancer 16:431-446. https://doi.org/10.1038/nrc. 2016.52

17. De Craene B, Berx G (2013) Regulatory networks defining EMT during cancer initiation and progression. Nat Rev Cancer 13:97-110. https://doi.org/ 10.1038/nrc3447

18. Di leva A, Rotondo F, Syro LV, Cusimano MD, Kovacs K (2014) Aggressive pituitary adenomas--diagnosis and emerging treatments. Nat Rev Endocrinol 10:423-435. https://doi.org/10.1038/nrendo.2014.64

19. Florio T, Casagrande S, Diana F, Bajetto A, Porcile C, Zona G, Thellung S, Arena S, Pattarozzi A, Corsaro A, Spaziante R, Robello M, Schettini G (2006) Chemokine stromal cell-derived factor lalpha induces proliferation and growth hormone release in $\mathrm{GH} 4 \mathrm{C} 1$ rat pituitary adenoma cell line through multiple intracellular signals. Mol Pharmacol 69:539-546. https://doi.org/10. 1124/mol.105.015255

20. Fornari MC, Palacios MF, Diez RA, Intebi AD (1994) Decreased chemotaxis of neutrophils in acromegaly and hyperprolactinemia. Eur J Endocrinol 130: 463-468

21. Fujiwara K, Yatabe M, Tofrizal A, Jindatip D, Yashiro T, Nagai R (2017) Identification of M2 macrophages in anterior pituitary glands of normal rats and rats with estrogen-induced prolactinoma. Cell Tissue Res 368:371-378. https://doi.org/10.1007/s00441-016-2564-x

22. Gevrey JC, Isaac BM, Cox D (2005) Syk is required for monocyte/ macrophage chemotaxis to CX3CL1 (Fractalkine). J Immunol 175:3737-3745

23. Green VL, Atkin SL, Speirs V, Jeffreys RV, Landolt AM, Mathew B, Hipkin L, White MC (1996) Cytokine expression in human anterior pituitary adenomas. Clin Endocrinol 45:179-185

24. Grizzi F, Borroni EM, Vacchini A, Qehajaj D, Liquori M, Stifter S, ChirivaInternati M, Di leva A (2015) Pituitary adenoma and the chemokine network: 
a systemic view. Front Endocrinol (Lausanne) 6:141. https://doi.org/10.3389/ fendo.2015.00141

25. Hadrup S, Donia M, Thor Straten P (2013) Effector CD4 and CD8 T cells and their role in the tumor microenvironment. Cancer Microenviron 6:123-133. https://doi.org/10.1007/s12307-012-0127-6

26. Han S, Zhang C, Li Q, Dong J, Liu Y, Huang Y, Jiang T, Wu A (2014) Tumourinfiltrating CD4(+) and CD8(+) lymphocytes as predictors of clinical outcome in glioma. Br J Cancer 110:2560-2568. https:/doi.org/10.1038/bjc.2014.162

27. Hao NB, Lu MH, Fan YH, Cao YL, Zhang ZR, Yang SM (2012) Macrophages in tumor microenvironments and the progression of tumors. Clin Dev Immunol 2012:948098. https://doi.org/10.1155/2012/948098

28. Heshmati HM, Kujas M, Casanova S, Wollan PC, Racadot J, Van Effenterre $R_{\text {, }}$ Derome PJ, Turpin G (1998) Prevalence of lymphocytic infiltrate in 1400 pituitary adenomas. Endocr J 45:357-361

29. Hume DA, Halpin D, Charlton H, Gordon S (1984) The mononuclear phagocyte system of the mouse defined by immunohistochemical localization of antigen F4/80: macrophages of endocrine organs. Proc Natl Acad Sci U S A 81:4174-4177

30. Jacobs JF, Idema AJ, Bol KF, Nierkens S, Grauer OM, Wesseling P, Grotenhuis JA, Hoogerbrugge PM, de Vries IJ, Adema GJ (2009) Regulatory T cells and the PD-L1/PD-1 pathway mediate immune suppression in malignant human brain tumors. Neuro-Oncology 11:394-402. https://doi.org/10.1215/ 15228517-2008-104

31. Kawamoto H, Uozumi T, Kawamoto K, Arita K, Yano T, Hirohata T (1996) Type IV collagenase activity and cavernous sinus invasion in human pituitary adenomas. Acta Neurochir 138:390-395

32. Kleinman HK, Martin GR (2005) Matrigel: basement membrane matrix with biological activity. Semin Cancer Biol 15:378-386. https://doi.org/10.1016/j. semcancer.2005.05.004

33. Lee Y, Kim JM, Lee EJ (2008) Functional expression of CXCR4 in somatotrophs: CXCL12 activates GH gene, GH production and secretion, and cellular proliferation. J Endocrinol 199:191-199. https://doi.org/10.1677/JOE-08-0250

34. Lima L, Oliveira D, Tavares A, Amaro T, Cruz R, Oliveira MJ, Ferreira JA, Santos $L$ (2014) The predominance of M2-polarized macrophages in the stroma of low-hypoxic bladder tumors is associated with BCG immunotherapy failure. Urol Oncol 32:449-457. https://doi.org/10.1016/j. urolonc.2013.10.012

35. Lin AL, Jonsson P, Tabar V, Yang TJ, Cuaron J, Beal K, Cohen M, Postow M, Rosenblum M, Shia J, DeAngelis LM, Taylor BS, Young RJ, Geer EB (2018) Marked response of a Hypermutated ACTH-secreting pituitary carcinoma to Ipilimumab and Nivolumab. J Clin Endocrinol Metab 103:3925-3930. https:// doi.org/10.1210/jc.2018-01347

36. Liu HY, Gu WJ, Wang CZ, Ji XJ, Mu YM (2016) Matrix metalloproteinase-9 and -2 and tissue inhibitor of matrix metalloproteinase-2 in invasive pituitary adenomas: a systematic review and meta-analysis of case-control trials. Medicine (Baltimore) 95:e3904. https://doi.org/10.1097/MD.0000000000003904

37. Lu JQ, Adam B, Jack AS, Lam A, Broad RW, Chik CL (2015) Immune cell infiltrates in pituitary adenomas: more macrophages in larger adenomas and more T cells in growth hormone adenomas. Endocr Pathol 26:263-272. https://doi.org/10.1007/s12022-015-9383-6

38. Lupi I, Manetti L, Caturegli P, Menicagli M, Cosottini M, lannelli A, Acerbi G, Bevilacqua G, Bogazzi F, Martino E (2010) Tumor infiltrating lymphocytes but not serum pituitary antibodies are associated with poor clinical outcome after surgery in patients with pituitary adenoma. J Clin Endocrinol Metab 95:289-296. https://doi.org/10.1210/jc.2009-1583

39. Mander TH, Morris JF (1996) Development of microglia and macrophages in the postnatal rat pituitary. Cell Tissue Res 286:347-355

40. Mantovani A, Allavena P, Sica A, Balkwill F (2008) Cancer-related inflammation. Nature 454:436-444. https://doi.org/10.1038/nature07205

41. Mantovani A, Savino B, Locati M, Zammataro L, Allavena P, Bonecchi R (2010) The chemokine system in cancer biology and therapy. Cytokine Growth Factor Rev 21:27-39. https://doi.org/10.1016/j.cytogfr.2009.11.007

42. Mantovani A, Schioppa T, Porta C, Allavena P, Sica A (2006) Role of tumorassociated macrophages in tumor progression and invasion. Cancer Metastasis Rev 25:315-322. https://doi.org/10.1007/s10555-006-9001-7

43. Mantovani A, Sica A, Sozzani S, Allavena P, Vecchi A, Locati M (2004) The chemokine system in diverse forms of macrophage activation and polarization. Trends Immunol 25:677-686. https://doi.org/10.1016/j.it.2004.09.015

44. Mantovani A, Sozzani S, Locati M, Allavena P, Sica A (2002) Macrophage polarization: tumor-associated macrophages as a paradigm for polarized M2 mononuclear phagocytes. Trends Immunol 23:549-555
45. Marques P, Barry S, Ronaldson A, Ogilvie A, Storr HL, Goadsby PJ, Powell M, Dang MN, Chahal HS, Evanson J, Kumar AV, Grieve J, Korbonits M (2018) Emergence of pituitary adenoma in a child during surveillance: clinical challenges and the family Members' view in an AIP mutation-positive family. Int J Endocrinol 2018:8581626. https://doi.org/10.1155/2018/8581626

46. Marques P, Korbonits M (2017) Genetic aspects of pituitary adenomas. Endocrinol Metab Clin N Am 46:335-374. https://doi.org/10.1016/j.ecl. 2017.01.004

47. Marques P, Barry S, Carlsen E, Collier D, Ronaldson A, Awad S, Dorward N, Grieve J, Mendoza N, Muquit S, Grossman AB, Balkwill F, Korbonits M (2019) Pituitary tumour fibroblast-derived cytokines influence tumour aggressiveness. Endocr Relat Cancer. https://doi.org/10.1530/ERC-19-0327

48. Massa A, Casagrande S, Bajetto A, Porcile C, Barbieri F, Thellung S, Arena S, Pattarozzi A, Gatti M, Corsaro A, Robello M, Schettini G, Florio T (2006) SDF-1 controls pituitary cell proliferation through the activation of ERK1/2 and the Ca2+-dependent, cytosolic tyrosine kinase Pyk2. Ann N Y Acad Sci 1090: 385-398. https://doi.org/10.1196/annals.1378.042

49. Mauri C, Bosma A (2012) Immune regulatory function of B cells. Annu Rev Immunol 30:221-241. https://doi.org/10.1146/annurev-immunol020711-074934

50. McKayed KK, Simpson JC (2013) Actin in action: imaging approaches to study cytoskeleton structure and function. Cells 2:715-731. https://doi.org/ 10.3390/cells2040715

51. Medrek C, Ponten F, Jirstrom K, Leandersson K (2012) The presence of tumor associated macrophages in tumor stroma as a prognostic marker for breast cancer patients. BMC Cancer 12:306. https://doi.org/10.1186/14712407-12-306

52. Mei Y, Bi WL, Greenwald NF, Du Z, Agar NY, Kaiser UB, Woodmansee WW, Reardon DA, Freeman GJ, Fecci PE, Laws ER Jr, Santagata S, Dunn GP, Dunn IF (2016) Increased expression of programmed death ligand 1 (PD-L1) in human pituitary tumors. Oncotarget 7:76565-76576. https://doi.org/10. 18632/oncotarget.12088

53. Molitch ME (2017) Diagnosis and treatment of pituitary adenomas: a review. JAMA 317:516-524. https://doi.org/10.1001/jama.2016.19699

54. Muraille E, Leo O, Moser M (2014) TH1/TH2 paradigm extended: macrophage polarization as an unappreciated pathogen-driven escape mechanism? Front Immunol 5:603. https://doi.org/10.3389/ fimmu.2014.00603

55. Nahrendorf M, Swirski FK (2016) Abandoning M1/M2 for a network model of macrophage function. Circ Res 119:414-417. https://doi.org/10.1161/ CIRCRESAHA. 116.309194

56. Newman AM, Liu CL, Green MR, Gentles AJ, Feng W, Xu Y, Hoang CD, Diehn M, Alizadeh AA (2015) Robust enumeration of cell subsets from tissue expression profiles. Nat Methods 12:453-457. https://doi.org/10. 1038/nmeth.3337

57. Nie J, Huang GL, Deng SZ, Bao Y, Liu YW, Feng ZP, Wang CH, Chen M, Qi ST, Pan J (2017) The purine receptor P2X7R regulates the release of proinflammatory cytokines in human craniopharyngioma. Endocr Relat Cancer 24:287-296. https://doi.org/10.1530/ERC-16-0338

58. Nomura R, Yoshida D, Teramoto A (2009) Stromal cell-derived factor-1 expression in pituitary adenoma tissues and upregulation in hypoxia. J Neuro-Oncol 94:173-181. https://doi.org/10.1007/s11060-009-9835-2

59. Olkhanud PB, Damdinsuren B, Bodogai M, Gress RE, Sen R, Wejksza K, Malchinkhuu E, Wersto RP, Biragyn A (2011) Tumor-evoked regulatory B cells promote breast cancer metastasis by converting resting $\mathrm{CD} 4(+) \mathrm{T}$ cells to T-regulatory cells. Cancer Res 71:3505-3515. https://doi.org/10.1158/00085472. CAN-10-4316

60. Ong SM, Tan YC, Beretta O, Jiang D, Yeap WH, Tai JJ, Wong WC, Yang H, Schwarz H, Lim KH, Koh PK, Ling KL, Wong SC (2012) Macrophages in human colorectal cancer are pro-inflammatory and prime T cells towards an anti-tumour type-1 inflammatory response. Eur J Immunol 42:89-100. https://doi.org/10.1002/eji.201141825

61. Powell DR, Huttenlocher A (2016) Neutrophils in the tumor microenvironment. Trends Immunol 37:41-52. https://doi.org/10.1016/j. it.2015.11.008

62. Qiu L, He D, Fan X, Li Z, Liao C, Zhu Y, Wang H (2011) The expression of interleukin (IL)-17 and IL-17 receptor and MMP-9 in human pituitary adenomas. Pituitary 14:266-275. https://doi.org/10.1007/s11102-011-0292-5

63. Reichel CA, Rehberg M, Lerchenberger M, Berberich N, Bihari P, Khandoga AG, Zahler S, Krombach F (2009) CCl2 and Ccl3 mediate neutrophil recruitment via induction of protein synthesis and generation of lipid 
mediators. Arterioscler Thromb Vasc Biol 29:1787-1793. https://doi.org/10. 1161/ATVBAHA.109.193268

64. Richardson TE, Shen ZJ, Kanchwala M, Xing C, Filatenkov A, Shang P, Barnett S, Abedin Z, Malter JS, Raisanen JM, Burns DK, White CL, Hatanpaa KJ (2017) Aggressive behavior in silent subtype III pituitary adenomas may depend on suppression of local immune response: a whole Transcriptome analysis. J Neuropathol Exp Neurol 76:874-882. https://doi.org/10.1093/jnen/nlx072

65. Rossi ML, Jones NR, Esiri MM, Havas L, al Izi M, Coakham HB (1990) Mononuclear cell infiltrate and HLA-Dr expression in 28 pituitary adenomas. Tumori 76:543-547

66. Ryder M, Ghossein RA, Ricarte-Filho JC, Knauf JA, Fagin JA (2008) Increased density of tumor-associated macrophages is associated with decreased survival in advanced thyroid cancer. Endocr Relat Cancer 15:1069-1074. https://doi.org/10.1677/ERC-08-0036

67. Sandhu SK, Papadopoulos K, Fong PC, Patnaik A, Messiou C, Olmos D, Wang G, Tromp BJ, Puchalski TA, Balkwill F, Berns B, Seetharam S, de Bono JS, Tolcher AW (2013) A first-in-human, first-in-class, phase I study of carlumab (CNTO 888), a human monoclonal antibody against CC-chemokine ligand 2 in patients with solid tumors. Cancer Chemother Pharmacol 71:1041-1050. https://doi.org/10.1007/s00280-013-2099-8

68. Sato M, Tamura R, Tamura H, Mase T, Kosugi K, Morimoto Y, Yoshida K, Toda M (2019) Analysis of tumor angiogenesis and immune microenvironment in nonfunctional pituitary endocrine tumors. J Clin Med 8. https://doi.org/10.3390/ jcm8050695

69. Schioppa T, Moore R, Thompson RG, Rosser EC, Kulbe H, Nedospasov S, Mauri C, Coussens LM, Balkwill FR (2011) B regulatory cells and the tumorpromoting actions of TNF-alpha during squamous carcinogenesis. Proc Natl Acad Sci U S A 108:10662-10667. https://doi.org/10.1073/pnas.1100994108

70. Semeraro M, Adam J, Stoll G, Louvet E, Chaba K, Poirier-Colame V, Sauvat A, Senovilla L, Vacchelli E, Bloy N, Humeau J, Buque A, Kepp O, Zitvogel L, Andre F, Mathieu MC, Delaloge S, Kroemer G (2016) The ratio of CD8(+ )/FOXP3 T lymphocytes infiltrating breast tissues predicts the relapse of ductal carcinoma in situ. Oncoimmunology 5:e1218106. https://doi.org/10. 1080/2162402X.2016.1218106

71. Singhal S, Stadanlick J, Annunziata MJ, Rao AS, Bhojnagarwala PS, O'Brien S, Moon EK, Cantu E, Danet-Desnoyers G, Ra HJ, Litzky L, Akimova T, Beier UH, Hancock WW, Albelda SM, Eruslanov EB (2019) Human tumor-associated monocytes/macrophages and their regulation of T cell responses in early-stage lung cancer. Sci Transl Med 11. https://doi.org/10.1126/scitranslmed.aat1500

72. Slaney CY, Kershaw MH, Darcy PK (2014) Trafficking of T cells into tumors. Cancer Res 74:7168-7174. https://doi.org/10.1158/0008-5472.CAN-14-2458

73. Steidl C, Lee T, Shah SP, Farinha P, Han G, Nayar T, Delaney A, Jones SJ, labal J, Weisenburger DD, Bast MA, Rosenwald A, Muller-Hermelink HK, Rimsza LM, Campo E, Delabie J, Braziel RM, Cook JR, Tubbs RR, Jaffe ES, Lenz G, Connors JM, Staudt LM, Chan WC, Gascoyne RD (2010) Tumor-associated macrophages and survival in classic Hodgkin's lymphoma. N Engl J Med 362:875-885. https://doi.org/10.1056/NEJMoa0905680

74. Stoll G, Bindea G, Mlecnik B, Galon J, Zitvogel L, Kroemer G (2015) Metaanalysis of organ-specific differences in the structure of the immune infiltrate in major malignancies. Oncotarget 6:11894-11909. https://doi.org/ 10.18632/oncotarget.4180

75. Stoll G, Zitvogel L, Kroemer G (2016) Differences in the composition of the immune infiltrate in breast cancer, colorectal carcinoma, melanoma and nonsmall cell lung cancer: a microarray-based meta-analysis. Oncoimmunology 5: e1067746. https://doi.org/10.1080/2162402X.2015.1067746

76. Suliman ME, Royds JA, Baxter L, Timperley WR, Cullen DR, Jones TH (1999) IL-8 mRNA expression by in situ hybridisation in human pituitary adenomas. Eur J Endocrinol 140:155-158

77. Suzuki H, Chikazawa N, Tasaka T, Wada J, Yamasaki A, Kitaura Y, Sozaki M, Tanaka M, Onishi H, Morisaki T, Katano M (2010) Intratumoral CD8(+) T/ FOXP3 (+) cell ratio is a predictive marker for survival in patients with colorectal cancer. Cancer Immunol Immunother 59:653-661. https://doi.org/ 10.1007/s00262-009-0781-9

78. Takano S, Akutsu H, Hara T, Yamamoto T, Matsumura A (2014) Correlations of vascular architecture and angiogenesis with pituitary adenoma histotype. Int J Endocrinol 2014:989574. https://doi.org/10.1155/2014/989574

79. Tecimer T, Dlott J, Chuntharapai A, Martin AW, Peiper SC (2000) Expression of the chemokine receptor CXCR2 in normal and neoplastic neuroendocrine cells. Arch Pathol Lab Med 124:520-525. https://doi.org/10. 1043/0003-9985(2000)124<0520:EOTCRC>2.0.CO;2

80. Tjiu JW, Chen JS, Shun CT, Lin SJ, Liao YH, Chu CY, Tsai TF, Chiu HC, Dai YS, Inoue H, Yang PC, Kuo ML, Jee SH (2009) Tumor-associated macrophage- induced invasion and angiogenesis of human basal cell carcinoma cells by cyclooxygenase-2 induction. J Invest Dermatol 129:1016-1025. https://doi. org/10.1038/jid.2008.310

81. Troiano G, Caponio VCA, Adipietro I, Tepedino M, Santoro R, Laino L, Lo Russo L, Cirillo N, Lo Muzio L (2019) Prognostic significance of CD68(+) and CD163(+) tumor associated macrophages in head and neck squamous cell carcinoma: a systematic review and meta-analysis. Oral Oncol 93:66-75. https://doi.org/10.1016/j.oraloncology.2019.04.019

82. Trouillas J, Roy P, Sturm N, Dantony E, Cortet-Rudelli C, Viennet G, Bonneville JF, Assaker R, Auger C, Brue T, Cornelius A, Dufour H, Jouanneau E, Francois P, Galland F, Mougel F, Chapuis F, Villeneuve L, Maurage CA, Figarella-Branger D, Raverot $G$, members of $H$, Barlier A, Bernier M, Bonnet $F$, Borson-Chazot F, Brassier G, Caulet-Maugendre S, Chabre O, Chanson P, Cottier JF, Delemer B, Delgrange E, Di Tommaso L, Eimer S, Gaillard S, Jan M, Girard JJ, Lapras V, Loiseau H, Passagia JG, Patey M, Penfornis A, Poirier JY, Perrin G, Tabarin A (2013) A new prognostic clinicopathological classification of pituitary adenomas: a multicentric case-control study of 410 patients with 8 years post-operative follow-up. Acta Neuropathol 126:123135. https://doi.org/10.1007/s00401-013-1084-y

83. Turner HE, Harris AL, Melmed S, Wass JA (2003) Angiogenesis in endocrine tumors. Endocr Rev 24:600-632. https://doi.org/10.1210/er.2002-0008

84. Vindelov SD, Hartoft-Nielsen ML, Rasmussen AK, Bendtzen K, Kosteljanetz M, Andersson AM, Feldt-Rasmussen U (2011) Interleukin-8 production from human somatotroph adenoma cells is stimulated by interleukin-1beta and inhibited by growth hormone releasing hormone and somatostatin. Growth Hormon IGF Res 21:134-139. https://doi.org/10.1016/.ghir.2011.03.005

85. Wang PF, Wang TJ, Yang YK, Yao K, Li Z, Li YM, Yan CX (2018) The expression profile of PD-L1 and CD8(+) lymphocyte in pituitary adenomas indicating for immunotherapy. J Neuro-Oncol 139:89-95. https://doi.org/10. 1007/s11060-018-2844-2

86. Waugh DJ, Wilson C (2008) The interleukin-8 pathway in cancer. Clin Cancer Res 14:6735-6741. https://doi.org/10.1158/1078-0432.CCR-07-4843

87. Wei IH, Harmon CM, Arcerito M, Cheng DF, Minter RM, Simeone DM (2014) Tumor-associated macrophages are a useful biomarker to predict recurrence after surgical resection of nonfunctional pancreatic neuroendocrine tumors. Ann Surg 260:1088-1094. https://doi.org/10.1097/ SLA.00000000000000262

88. Xing B, Kong YG, Yao Y, Lian W, Wang RZ, Ren ZY (2013) Study on the expression levels of CXCR4, CXCL12, CD44, and CD147 and their potential correlation with invasive behaviors of pituitary adenomas. Biomed Environ Sci 26:592-598. https://doi.org/10.3967/0895-3988.2013.07.011

89. Yapa S, Mulla O, Green V, England J, Greenman J (2017) The role of chemokines in thyroid carcinoma. Thyroid 27:1347-1359. https://doi.org/10. 1089/thy.2016.0660

90. Yoshida D, Koketshu K, Nomura R, Teramoto A (2010) The CXCR4 antagonist AMD3100 suppresses hypoxia-mediated growth hormone production in GH3 rat pituitary adenoma cells. J Neuro-Oncol 100:51-64. https:/doi.org/ 10.1007/s11060-010-0152-6

91. Yoshida D, Nomura R, Teramoto A (2009) Signalling pathway mediated by CXCR7, an alternative chemokine receptor for stromal-cell derived factor1alpha, in AtT20 mouse adrenocorticotrophic hormone-secreting pituitary adenoma cells. J Neuroendocrinol 21:481-488. https://doi.org/10.1111/j. 1365-2826.2009.01867.x

92. Zhang X, Zhang W, Yuan X, Fu M, Qian H, Xu W (2016) Neutrophils in cancer development and progression: roles, mechanisms, and implications (review). Int J Oncol 49:857-867. https://doi.org/10.3892/ijo.2016.3616

\section{Publisher's Note}

Springer Nature remains neutral with regard to jurisdictional claims in published maps and institutional affiliations. 